\title{
An open-source surface barrier discharge plasma pretreatment for reduced cracking of outdoor wood coatings
}

\author{
Sebastian Dahle (D) Megi Pilko · Jure Žigon (1) - Rok Zaplotnik • \\ Marko Petrič $\cdot$ Matjaž Pavlič
}

Received: 22 December 2020/ Accepted: 12 June 2021 / Published online: 6 July 2021

(C) The Author(s) 2021

\begin{abstract}
The development of a simple surface barrier discharge plasma device is presented to enable more widespread access to and utilization of plasma technology. The application of the plasma device was demonstrated for pretreatment of wood prior to application of protective coatings for outdoor usage. The coatings' overall performance was increased, showing a reduction or absence of cracking due to weathering on plasma-pretreated specimens.
\end{abstract}

Moreover, after ten months of outdoor weathering, the plasma-pretreated specimens showed fewer infections with biotic factors and improved adhesion performance in cross-cut tests, while the surface gloss performed independently from plasma pretreatment. In contrast to that, plasma-pretreated specimens were slightly more prone to discoloration due to outdoor weathering, whereas the plasma pretreatment did not impact the initial color after coating application.

Supplementary Information The online version contains supplementary material available at https://doi.org/10.1007/ s10570-021-04014-2.

S. Dahle $(\varangle) \cdot$ M. Pilko · J. Žigon .

M. Petrič · M. Pavlič

Department of Wood Science and Technology,

Biotechnical Faculty, University of Ljubljana,

Jamnikarjeva ulica 101, 1000 Ljubljana, Slovenia

e-mail: Sebastian.dahle@bf.uni-lj.si

R. Zaplotnik

Department of Surface Engineering, Jožef Stefan Institute,

Jamova cesta 39, 1000 Ljubljana, Slovenia 


\section{Graphic abstract}

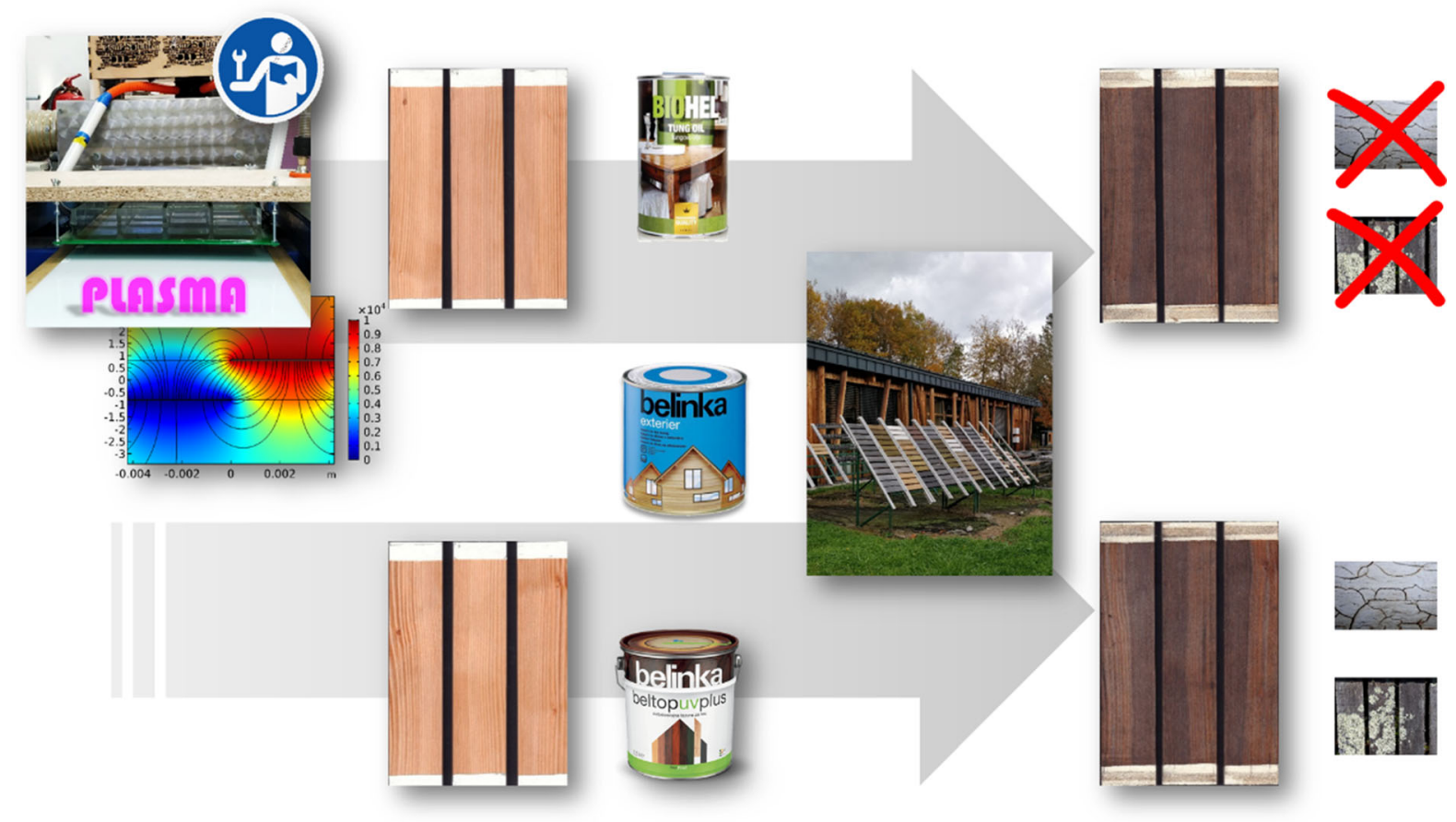

Keywords Non-thermal plasma - Spruce wood . Outdoor aging $\cdot$ Open lab equipment

\section{Introduction}

The first technical applications of plasmas date back at least until the middle of the nineteenth century (c.f. Kogelschatz 2003), but have only been used on larger scales for the surface modification of workpieces since amidst the twentieth century. In many technical plasmas, the fraction of ionized gas particles (degree of ionization) is relatively low and can be well below $0.1 \%$. However, the electron energies can be well above $10 \mathrm{eV}$, corresponding to an electron temperature of well above $10,000 \mathrm{~K}$, as opposed to the temperature of the neutral gas particles that remains close to room temperature (Kogelschatz 2003). These gas discharges are not in thermal equilibrium and are hence called non-thermal plasmas. The physical and chemical processes inside the plasma gas are complex and include e.g. ionization and recombination, light emission, dissociation of molecules, and gas particles' excitation to high vibrational states (Lieberman and Lichtenberg 2005). Thereby, various reactive gas species are generated, which can be utilized for the treatment and functionalization of solid materials (Fridman 2008). Among various ways to generate a plasma discharge, those techniques that operate at atmospheric pressure are of particular interest for many practical applications in surface engineering, but with particular broad industrial impact on polymer materials (Thomas and Mittal 2013). The main atmospheric plasma technologies for surface engineering are Corona discharges, dielectric barrier discharges (DBD), and a variety of plasma jets for remote treatments (Harry 2010).

The available atmospheric plasma techniques have specific advantages and disadvantages, which render individual methods suited for specific applications (Fridman 2008). In particular, remote plasmas and plasma jets provide the advantage of localized treatments that are mostly independent of substrate shapes and geometries. However, the scale-up for large areas often is problematic and cost-intensive. Corona 
discharges are in use for the longest times among atmospheric non-thermal plasmas and can be very energy-efficient. In comparison, DBD offer the best scalability of treatment area and control of discharge processes even at high power input. Despite their high effectiveness, however, direct DBD setups can be limited in their applicability, as non-conductive substrates need to be passed through the discharge area and are thus limited in thickness. One solution to overcome these limitations are surface barrier discharges (SBD), which utilize the principle of a DBD to ignite the plasma on the surface of an electrode structure.

The SBD technology became particularly popular after the diffuse coplanar surface barrier discharge (DCSBD) was developed in 2002 (Šimor et al. 2002). This high-power setup with a diffuse discharge appearance enables overcoming of inhomogeneities potentially arising from the microdischarge structure of barrier discharges (Ráhel' and Sherman 2005; Čech et al. 2015), thus achieving highly homogeneous treatments and an enhanced scalability of the technology (Štěpánová et al. 2017). The discharge has since been intensely investigated and characterized, including by mass spectrometry (Lazovic et al 2008; Čech et al. 2017), optical emission spectroscopy (Čech et al. 2008; Tučeková et al. 2013), energy flux measurements (Hansen et al. 2019), cross-correlation spectroscopy (Hoder et al. 2008, 2009), numerical simulations and fast optical imaging (Čech et al. 2014). Design considerations include the thickness of the dielectric barrier (Čech et al. 2014). Moreover, systemic influences on the discharge properties were found for the electrode gap (Čech et al. 2009) and the electrode temperature (Čech et al. 2007), which therefore need to be well controlled to achieve the best possible repeatability of plasma treatment outcomes.

Other designs of SBDs can encompass various electrode designs (Akamatsu 2014) or include gas feed possibilities through patterned perforations (Gogolides et al. 2016), typically with radio-frequency excitation (Dedrick et al. 2011) to avoid electrode damage by arc formation and to ensure a homogeneous discharge (Dimitrakellis et al. 2016). Such systems can be employed equally well for surface functionalization (Zeniou et al. 2017). Moreover, the included gas feed allows for a simple implementation of etching, coating, or other processes that require special working gases (Dimitrakellis et al. 2017).

The benefits of surface discharges are especially prominent with the treatment of work pieces with very flat surfaces and large surface areas (Černák et al. 2009). That way, many industrial applications for plasma treatments can be arranged with great energy efficiency (Kelar et al. 2015) and at high processing speeds (Černák et al. 2011).

The plasma treatments using SBDs and particularly the DCSBD are well demonstrated on all materials' classes and types of work pieces, including glass (Homola et al. 2013; Štěpánová et al. 2015), metal sheets (Prysiazhnyi and Cernak 2012), or textiles (Radić et al. 2009). The applications can further include the generation and depositions of functional nanoparticles (Radić et al. 2013), improved germination of seeds (Šerá et al. 2021), or inactivation of fungi and germs (Mošovská et al. 2019).

Plasma applications on wood materials were pioneered in the 1970s by Kim and Goring (1971) with the plasma-enhanced bonding of wood and synthetic polymers, and by Bialski et al. (1975) with the plasma-enhanced wood wettability. Most applications of the time used atmospheric corona plasmas and low-pressure radio-frequency plasmas (Denes et al. 2005; Hill 2007). When further technologies such as barrier discharges and gliding arc jets became available, scientific studies on wood treatments increased again around 2010 (Viöl et al. 2012; Petrič 2013).

In general, plasma technology is used with woodbased biomaterials to enhance gluing, composites, and coatings (Žigon et al. 2018). Plasma pretreatments were shown to improve adhesion strengths (Král et al. 2015; Žigon et al. 2020a), while reducing susceptibility to humidity (Avramidis et al. 2010; Wascher et al. 2017) and weathering (Žigon et al. 2018). Further, plasma treatments can deposit functional coatings, such as super-hydrophobic, super-hydrophilic, or photocatalytic functional layers (Podgorski et al. 2001; Mai and Militz 2004; Wallenhorst et al. 2018). Moreover, plasma treatments can enhance compositing between different material classes, e.g. to bond wood and metals (Žigon et al. 2020a).

Surface barrier discharges and particularly the DCSBD were used on wood and wood-based substrates for many different applications, including activation (Odrášková, 2008; Ráhel' et al. 2011; Lux et al. 2013; Tino and Smatko 2014; Jablonský et al. 
2016) and the deposition of hydrophobic coatings (Odrášková et al. 2007). In addition to natural wood, similar effects were observed on paper (Talviste et al. 2019) as well as on thermally modified wood (Tóth et al. 2007). The activation is strongly limited by diffusion and chemical modifications were found no deeper than $330 \mathrm{~nm}$ into the surface (Král et al. 2015). Thereby, the effects are less pronounced than those of e.g. a plasma jet (Gerullis et al. 2018), but still yield a sufficient outcome as activation for gluing and coating applications.

The treatment of wood surfaces with air plasma discharges is an interesting technique also as pretreatment for improved performance of coatings, particularly for outdoor applications (Lukowsky and Horn 2002; Žigon et al. 2018). The available literature provides only limited insight into how aging in natural outdoor conditions is changing, if cost-effective plasma techniques are utilized together with typical outdoor coating systems.

Despite all the benefits offered by plasma technology, its utilization in many cases is still very limited. The high prices of industrial equipment present one particular hurdle to the operation and exploitation of this technology. This is the case particularly so with low value-added products and in industrial sectors with both, low profit margins and low external pressure for high-tech innovation. This can be enhanced by providing alternative solutions, e.g. through the free and open source technological development (Wijnen et al. 2014). As a part of the Open Science movement, the section on Open Lab Equipment is a growing environment that renders possible new applications and allows access to current high-tech developments for individual people, research groups, or companies with low funding. For plasma technology, most shared developments remained within the scientific communities and were not openly accessible (c.f. Schutze et al. 1998). For localized remote plasma treatments, this has since changed through the COST reference jet (Golda et al. 2016, 2018) and other openly published plasma sources (Yan et al. 2013).

In this publication, we describe a simple implementation for an open plasma device suited for largearea surface treatment. A potential application of the device is demonstrated on wooden substrates as a pretreatment for common wood finishes. Although some wood coatings have been studied before, a comparison of the impact of plasma pretreatments for several wooden finishes, such as oils and stains, has been lacking, so far (c.f. Žigon et al. 2018). Moreover, the nature of known plasma modification might indicate an effect of the plasma on the material's susceptibility to ultraviolet radiation, which is a major aesthetic factor related to protection of wood in outdoor application. Aesthetics and optical appearance of aged samples are compared with the impact of plasma treatments on other performance indicators, including biotic factors, cracking, and coating adhesion, as applicable to the used surface systems.

\section{Materials and methods}

\section{Substrate material}

In this study, spruce wood (Picea abies (L.) Karst.) specimens with dimensions $375 \mathrm{~mm} \times 80 \mathrm{~mm} \times 20$ $\mathrm{mm}$ with radial or semi-radial orientation of the fibers were used. In total, 32 specimens were conditioned under natural conditions at a temperature of $20{ }^{\circ} \mathrm{C}$ and a relative air humidity of $65 \%$. The surfaces of the samples were flat planed, without addition sanding or other primary processing.

Plasma treatments, COMSOL simulations and optical emission spectroscopy

Plasma pretreatment was carried out before application of different coatings, using a surface barrier discharge setup as described in "Results and discussion" section. The device was operated at a frequency of $10 \mathrm{kHz}$ with a $20 \%$ duty cycle and a primary voltage of $18.5 \mathrm{~V}$, leading to a primary current of 5.6 A. Samples were treated on a moving band at a feed belt speed of $0.15 \mathrm{~m} / \mathrm{s}$, resulting in a treatment time of $2.5 \mathrm{~s}$ for each spot on the specimen's surface or $3.79 \mathrm{~s}$ for the entire specimen. The distance between specimen and plasma electrode was optimized to $0.5 \mathrm{~mm}$, thus yielding a sufficient plasma effect, while avoiding mechanical contacts between the electrode and the samples. During the plasma treatment, the overall power consumption, including all electrical losses, averaged to $159.4 \mathrm{~W}$, amounting to $1.710^{-4} \mathrm{kWh}$ per specimen. This calculates to a specific power consumption of $5.710^{-3} \mathrm{kWh} / \mathrm{m}^{2}$ or Carbon dioxide emissions equivalents of $1.61 \mathrm{~g}_{\mathrm{CO} 2 \mathrm{eq}}$ l 
$\mathrm{m}^{2}$, assuming average specific emissions of $284 \mathrm{~g}_{\mathrm{CO} 2} /$ $\mathrm{kWh}$ for Slovenia (ElectricityMap 2020).

Electric field strength, electric displacement fields, and electric potentials have been calculated for different electrode configurations using the COMSOL Multiphysics ${ }^{\circledR}$ v5.3 (Comsol Multiphysics GmbH, Göttingen, Germany) electrostatics module. Although excluding plasma ignition and frequency-dependent effects represents a strong simplification, the analysis of static electric fields provides a good basis for the construction of DBD setups operated at relatively low frequencies (Žigon et al. 2019).

Optical emission spectroscopy (OES) has been used to evaluate the gas temperatures and electron energies in the plasma discharge. Spectra were recorded with $10 \mathrm{~s}$ integration time using a 16-bit Avantes AvaSpec 3648 fibre optic spectrometer (Avantes Inc., Louisville, CO, USA). Reduced electric fields have been evaluated from the nitrogen emission lines $\mathrm{N}_{2}{ }^{+}\left(\mathrm{B}^{2-}\right.$ $\left.\Sigma_{\mathrm{u}}{ }^{+} \rightarrow \mathrm{X}^{2} \Sigma_{\mathrm{g}}{ }^{+},(0,0)\right)$ at $391.4 \mathrm{~nm}$ and $\mathrm{N}_{2}\left(\mathrm{C}^{3} \Pi_{\mathrm{u}-}\right.$ $\left.\rightarrow \mathrm{B}^{3} \Pi_{\mathrm{g}},(2,5)\right)$ at $394.3 \mathrm{~nm}$ after Paris and colleagues (Paris et al. 2005, 2006; Pancheshnyi 2006; Kuchenbecker et al. 2009). Electron energies were calculated based on the reduced electric fields using the Bolsig + software version 03/2016 (Hagelaar and Pitchford 2005) with cross-sections from the LXcat database (Pitchford 2013). The DBD discharges in this study do not fulfil the steady-state conditions for the equations as formulated by Paris and co-authors (Paris et al. 2005). However, Bonaventura and colleagues (Bonaventura et al. 2011) proved that the equations are suited for determining accurate peak electric fields, and hence accurate peak values for average electron energies, as long as a sufficient spatial and time-integrated optical emission spectrum is used.

\section{Application of coatings}

In this study, three types of protective wood coatings for outdoor applications were used:

1. BIOHEL Tung oil (Helios TBLUS, d.o.o., Količevo, Slovenia) commercial colorless natural tung oil, a pure vegetable oil from Aleurites fordii Hemsl. (L.) fruits and seeds.

2. Belinka Exterier (Helios TBLUS, d.o.o., Količevo, Slovenia) transparent water-based stain including acrylic resin, ultraviolet (UV) light absorbers and nano-filters, weather-resistant pigments, water-repellent substances, film preservative, and additives.

3. Belinka Beltop UV Plus (Helios TBLUS, d.o.o., Količevo, Slovenia) colorless stain based on organic, non-aromatic solvents, alkyd resins, light and weather-resistant pigments, UV filters, UV absorbers, free radical scavengers, and waxes.

According to the manufacturer's instructions, all coatings were applied manually using a brush in two layers at a room temperature between 21 and $23{ }^{\circ} \mathrm{C}$, and a relative humidity between 52 and $67 \%$. Specimens were weighed before and after coating application to monitor the coating application, yielding average application rate in $\mathrm{g} / \mathrm{m}^{2}$ for the different sample systems given in Table 1 .

The averaged application rates from non-polar formulations show an increase on plasma-treated specimens by $21 \%$ for tung oil and $32 \%$ for the solvent-based UV stain, whereas the water-based stain's application rate was on average $29 \%$ lower on the plasma-treated specimens. The combined application rate of both coating applications on average increased by $11 \%$ and $31 \%$ on plasma-treated specimens for the tung oil and the solvent-based UV stain, respectively, whereas it was reduced by an average $19 \%$ on plasma-treated specimens for the water-based stain. In almost all cases, the standard deviation of the coating application rate was notably increased for the plasma-treated specimens in

Table 1 Average masses of applied coatings on untreated and plasma-pretreated spruce substrates

\begin{tabular}{llll}
\hline Coating & Pretreatment & $\begin{array}{l}\text { First } \\
\text { application } \\
\left(\mathrm{g} / \mathrm{m}^{2}\right)\end{array}$ & $\begin{array}{l}\text { Second } \\
\text { application } \\
\left(\mathrm{g} / \mathrm{m}^{2}\right)\end{array}$ \\
\hline Tung oil & Untreated & $66.2 \pm 7.9$ & $25.8 \pm 5.0$ \\
& Plasma & $80.3 \pm 35.6$ & $21.5 \pm 14.2$ \\
$\begin{array}{l}\text { Water-based } \\
\text { stain }\end{array}$ & Untreated & $249.5 \pm 26.4$ & $60.4 \pm 5.7$ \\
$\begin{array}{l}\text { Solvent-based, } \\
\text { UV protective } \\
\text { stain }\end{array}$ & Untreated & $103.1 \pm 19.2$ & $33.3 \pm 4.5$ \\
& & & \\
\hline
\end{tabular}


comparison with the correlated untreated specimens. While variations in application rate arised from the manual application, there seems to be a distinct impact by the plasma treatment. The influence of the plasma on both, average values and standard deviations of the application rates, are likely a consequence of the wellknown change in wetting and penetration that the plasma induces, and which is developing in dependence of the heterogeneous wood structure.

Contact angle measurements and plasma optimization

The plasma treatment parameters were optimized on the basis of water contact angle (WCA) measurements using a Theta optical goniometer (Biolin Scientific Oy, Espoo, Finland). Apparent WCAs were evaluated by Young-Laplace analysis using the software (OneAttension version 2.4 [r4931], Biolin Scientific). All together, 10 droplets for each type of sample were automatically analyzed within $63 \mathrm{~s}$ (1.7 images per second). The measurement started immediately after the first contact of the drop with the surface of the sample. Contact angle measurements were performed immediately after plasma treatment to avoid any effect of aging on the measured values. In comparison, additional WCAs were measured on reference samples that were neither coated nor plasma-treated.

Smaller specimens with dimensions $92 \mathrm{~mm} \times 80$ $\mathrm{mm} \times 20 \mathrm{~mm}$ were used to optimize the conditions and parameters of the plasma processing. In particular, we optimized the duration of the plasma treatment by varying the feed rate and the gap distance between electrode and surface of the specimens. Moreover, repetitive treatments from one to three passes were tested. Summarized results of the optimization are given in the complete dataset of raw and analyzed data (see data statement).

Table 2 Systematic structure of samples, treatments, coatings, and weathering
Natural aging under outdoor conditions

To prevent water absorption, the end-grain and side perimeter of all samples were sealed using a twocomponent thick-layer epoxy coating (EPOLOR HB, COLOR Medvode, Slovenia) before exposure to natural conditions after the coatings were cured for at least $24 \mathrm{~h}$. The sealing coating was applied in two coats with an intermediate $24 \mathrm{~h}$ drying time. Specimens were exposed according to the instructions of the standard SIST EN 927-3:2001, but the exposure period was reduced to 10 months, from August 19th, 2019, to June 18th, 2020. The weather and climate data collected by the Slovene Environmental Agency (Meteo 2020) on mean air temperature, temperature extremes, precipitation sums, and bright sunshine duration for the period of exposure is given in the Supplemental Material (Figures S2.1-S5.12). Monitoring measurements of color and gloss, as well as a scan of the specimens' surfaces, were performed after 1 month, 3 months, and after 6 months of the ongoing exposure. The samples were exposed on special stands with the longitudinal edge of the sample in a horizontal position, the test upper surface inclined by $45^{\circ}$, and the surfaces oriented towards the equator (south direction). Sample was positioned at a distance of $3 \mathrm{~cm}$ to ensure that rain running of any sample does not hit any sample below. The distance from the floor to the bottom pattern on the stand was $50 \mathrm{~cm}$. The stands were placed on a grassy surface at the Department of Wood Science of the Biotechnical Faculty, in a location where the effects of weather conditions were undisturbed, excluding shading from neighboring buildings and providing a free path to the effects of precipitation, wind, and sun.

The experimental plan included four specimens for each of three coatings and for uncoated spruce, each in both cases, with and without plasma pretreatment. For

\begin{tabular}{|c|c|c|c|c|c|c|c|c|c|}
\hline \multirow{6}{*}{$\begin{array}{l}\text { Table } 2 \text { Systematic } \\
\text { structure of samples, } \\
\text { treatments, coatings, and } \\
\text { weathering }\end{array}$} & \multirow{2}{*}{$\frac{\text { Coating }}{\text { Uncoated }}$} & \multicolumn{4}{|c|}{ Plasma-treated } & \multicolumn{4}{|c|}{ Untreated } \\
\hline & & U0p & U1p & $\mathrm{U} 2 \mathrm{p}$ & $\mathrm{U} 3 \mathrm{p}$ & U0n & U1n & $\mathrm{U} 2 \mathrm{n}$ & U3n \\
\hline & Tung oil & T0p & $\mathrm{T} 1 \mathrm{p}$ & $\mathrm{T} 2 \mathrm{p}$ & T3p & T0n & T1n & $\mathrm{T} 2 \mathrm{n}$ & $\mathrm{T} 3 \mathrm{n}$ \\
\hline & Water-based stain & W0p & $\mathrm{W} 1 \mathrm{p}$ & W2p & W3p & W0n & W1n & $\mathrm{W} 2 \mathrm{n}$ & W3n \\
\hline & Solvent-based UV stain & S0p & $\mathrm{S} 1 \mathrm{p}$ & $\mathrm{S} 2 \mathrm{p}$ & S3p & S0n & S1n & $\mathrm{S} 2 \mathrm{n}$ & $\mathrm{S} 3 \mathrm{n}$ \\
\hline & & Dark & \multicolumn{3}{|c|}{ Weathered } & Dark & \multicolumn{3}{|c|}{ Weathered } \\
\hline
\end{tabular}


each of these 16 sample systems, three specimens were exposed to weathering and one specimen was stored in a dark, enclosed space as a reference for later comparison with the exposed one. A systematic overview of the samples and short denominations is given in Table 2.

\section{Visual evaluation}

Surface cracking was assessed according to ISO 4628-4:1982. After removal from the stands, the specimens were gently wiped with a dry cloth to remove surface impurities accumulated from exposure to rainwater and other factors, thus allowing for a more clear assessment of the damage. The assessment consists of three parts and follows the principle of numerical and letter evaluation, using the following nomenclature. The first rating defines the extent of cracking $(0-$ no, $1-$ less than a few, 2-a few, 3medium, 4-medium dense, 5-dense). The second rating assesses the crack size (S1-visible only at $10 \times$ magnification, S2-barely visible to the naked eye, S3 - clearly visible to the naked eye, S4-large cracks up to $1 \mathrm{~mm}$ wide, S5-very large cracks with a width of more than $1 \mathrm{~mm}$ ). The third rating evaluates the crack depths (a-the top layer is not entirely cracked, b-the top layer is completely cracked, the bottom layer remains mostly undamaged, c-the entire coating system from the surface to the substrate is cracked).

According to the reference European standard EN 16492:2014, the extent of infection with biotic factors was evaluated. The assessment defines the deformation of the surface caused by the growth of fungi, molds and algae. The assessment consists of three parts and follows the principle of numerical evaluation. The first assessment defines the intensity of infection or change thereof within the observed area ( 0 - no visible growth, surface unchanged, 1 -little visible growth or very slight change, 2-clearly visible growth or slight change, 3-very clearly visible growth or moderate change, 4-very visible growth or significant change, 5-very pronounced growth). The second assessment takes into account the amount of infection ( 0 -no or no infection detected, 1 -very little or small, barely noticeable infection, 2-some or small but significant infection, 3-moderate infection, 4-significant infection, 5-dense sample of infection or homogeneous infection). The third assessment describes the percentage of infected area $(0-$ no growth on the surface of the sample, $1-$ up to $10 \%$ growth on the surface of the sample, 2 more than $10 \%$ up to and including $30 \%$ growth on the surface of the sample, 3-more than $30 \%$ up to and including $50 \%$ growth on the surface of the sample, 4 -more than 50\% up to and including 100\% growth on the surface of the sample).

No formation of bubbles, peeling, or chalking occurred on any specimen during our experiment's duration, so we did not perform an assessment of these damage types.

\section{Color and gloss measurements}

The gloss of all samples was measured before and periodically during the outdoor exposure following the SIST EN ISO 2813:1999 standard using an X-Rite (Grand Rapids, MI, USA) AcuGloss TRI gloss meter. On each sample's surface, 10 measurements were performed randomly (five measurements from one and five from the other direction of the sample). In this part of the test, we introduced minor adjustments to the standard, which in the original provides for six random measurements (three from one and three from the other direction of the sample), and in view of better results we decided to perform a larger number of measurements. They were performed at an angle of incident light of $60^{\circ}$, parallel to the wood fibers in the longitudinal direction. When measuring, areas of samples with natural surface staining or cramps were avoided, as this would have a negative impact on the final measurements. The results were given as the gloss change calculated from the difference between the average gloss measurements before and after exposure.

The samples' color was measured before and periodically during the outdoor exposure following the adapted standard ISO/DIS 7724-2:1997 using an X-Rite SP62 spectrophotometer with a standardized D65 light source. The CIELAB parameters $\left(L^{*}, a^{*}\right.$, and $\left.b^{*}\right)$, their changes $\left(\Delta L^{*}, \Delta a^{*}\right.$, and $\left.\Delta b^{*}\right)$, and the total colour change $\left(\Delta E^{*}\right)$ were determined after the CIEDE2000 formula (CIE 2000), using Eq. 1. These values were then arithmetically averaged for each sample.

$\Delta E^{*}=\sqrt{\left(\Delta L^{*}\right)^{2}+\left(\Delta a^{*}\right)^{2}+\left(\Delta b^{*}\right)^{2}}$ 


\section{Open-source plasma equipment}

Coating adhesion measurements

The coating adhesion was assessed in accordance with the SIST EN 927-3:2001 standard and later assessed according to the adjusted instructions from the SIST EN ISO 2409:1997 standard. Adjustments were made to the blade, using two special knives with six clamped blades instead of the single blade described in the standard. The distance between the clamped blades of the larger knife was $2 \mathrm{~mm}$ and the distance between the blades of the smaller knife was $1 \mathrm{~mm}$. With these, we achieved cross-cuts of two different sizes and, consequently, a more detailed assessment, obtained more accurate results on coatings' adhesion.

\section{Electrode configuration}

Most industrial equipment design electrodes for a long-time, high-intensity operation with minimal maintenance and thus choose ceramics as barrier materials (Čech et al. 2014). Simpler designs make use of polymeric or composite materials with sufficiently high breakthrough voltage, such as printed circuit boards (PCB) (Zeniou et al. 2017). These are typically made from fiberglass-epoxy composites, e.g. the FR4 laminate material. Although the epoxy tends to degrade over time, such electrodes are sufficiently stable for various plasma applications. Moreover, the low production costs at high qualities render them well applicable as consumables.

The design utilized in this study employs 2-layer 1.6 mm FR4 PCBs (JLCPCB, Shenzhen, Guangdong, China) with $35 \mu \mathrm{m}$ conductive traces, hot air solder
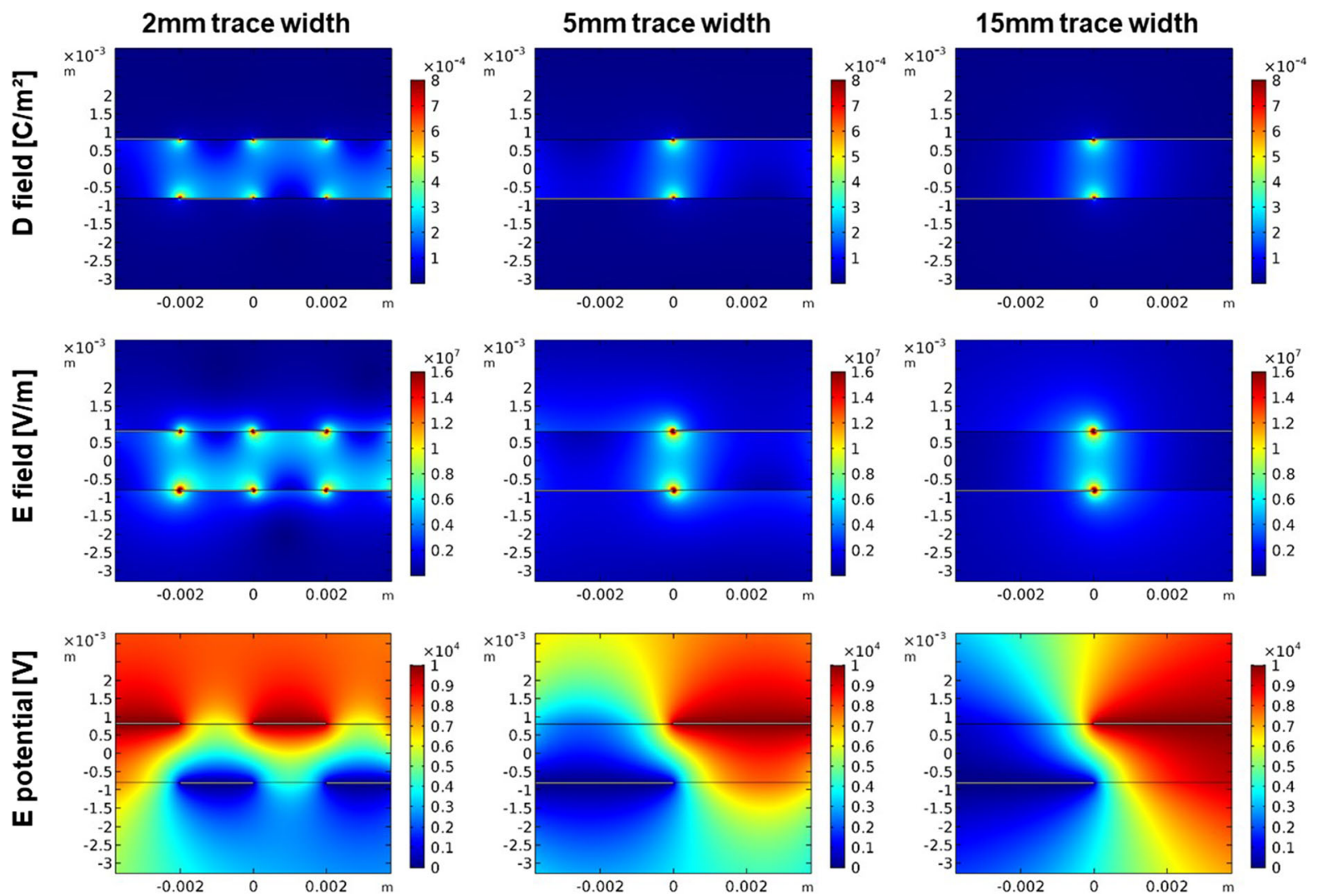

Fig. 1 COMSOL simulations of displacement field (top row), electric field (middle row), and electric potential distribution (bottom row) for electrode setups with $2 \mathrm{~mm}$ (left column), $5 \mathrm{~mm}$ (middle column), and $15 \mathrm{~mm}$ trace width (right column) 
leveling (HASL leveling), and an epoxy-based solder mask. Despite the solder mask protecting the conductive traces, the electrodes show degradation after extended treatments of substrates. Therefore, this design is not suited for continuous operation or industrial applications, whereas the service life is entirely appropriate for usage in laboratories or small workshop environments.

The electrode designs were initially optimized using simple electrostatic simulations as described in the "Materials and methods" section. Three pairs of alternating electrodes were simulated with trace widths between 1 and $20 \mathrm{~mm}$. Selected results for top electrodes at $10 \mathrm{kV}$ potential and bottom electrodes at ground potential are shown in Fig. 1. For small trace widths, the displacement fields exhibits considerable oblique fractions in-between adjacent electrodes, indicating a strong dielectric loss inside the FR4 carrier. At increasing trace width, the oblique fraction is reduced, approaching its minimum around $5 \mathrm{~mm}$ trace width. Above $5 \mathrm{~mm}$, the displacement field is concentrated in-between the edges of adjacent electrodes with negligible impact of further increasing the trace width. From the electric potentials (bottom row in Fig. 1) it is obvious that these are strongly concentrated around the electrode traces as long as the width is approx. in the same order of magnitude as the effective spacing between electrodes of alternate polarity, $d / \varepsilon_{\mathrm{r}}$, with the dielectric plate thickness $\mathrm{d}$ and the dielectric permittivity of the material $\varepsilon_{\mathrm{r}}$. Starting at a trace width of $5 \mathrm{~mm}$, the electric potential on the dielectric surface opposite of an electrode resembles at least $80 \%$ of the potential applied to the electrode trace relative to the potential of the opposite electrodes. This is accompanied by a reduction of the oblique $E$ field between opposite electrodes and an increase of the $E$ field around electrode corners, which extends into the surrounding air (middle row). At larger trace widths, the electric potential extents further towards the opposite side of the dielectric FR4 substrate, whereas the electric field strength around the edges of the electrode traces only shows a negligible increase above $5 \mathrm{~mm}$ trace width.

The effect of the trace width is further exemplified in Fig. 2, where the electric field strength is analyzed on several positions in dependence of the electrode traces' widths. The position of the line analyses are shown as red lines in the 2D model (Fig. 2, top row), above the corresponding $\mathrm{E}$ field data. The parameter study shows an increase of the electric field strength
Edge to edge
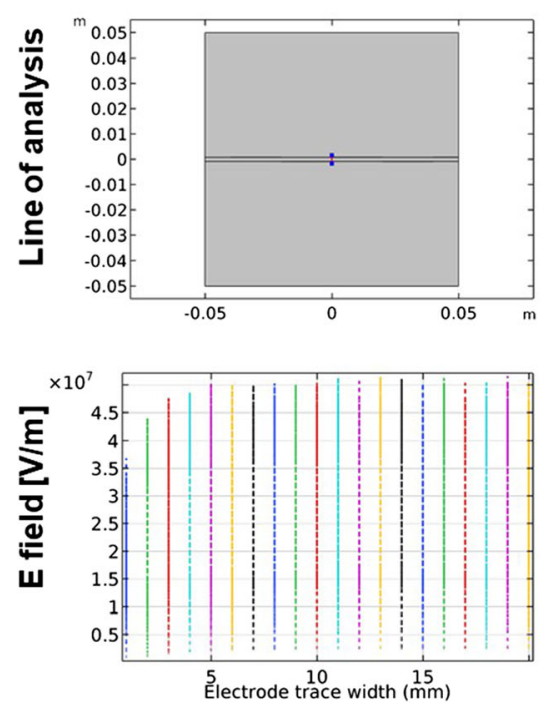

Electrode on center
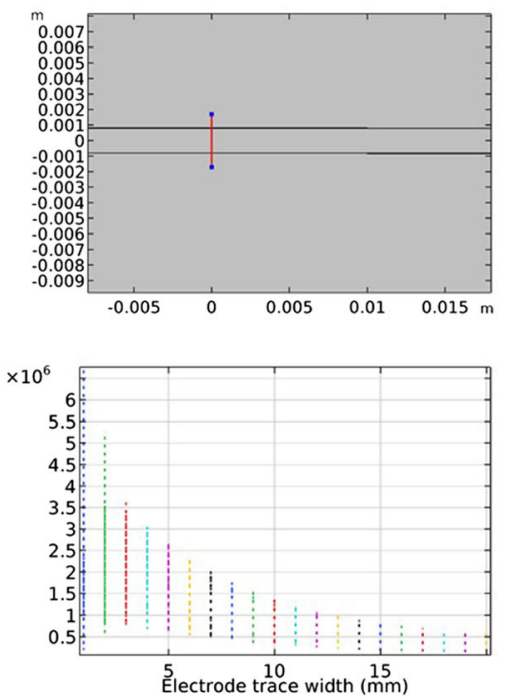

Tangential across edge
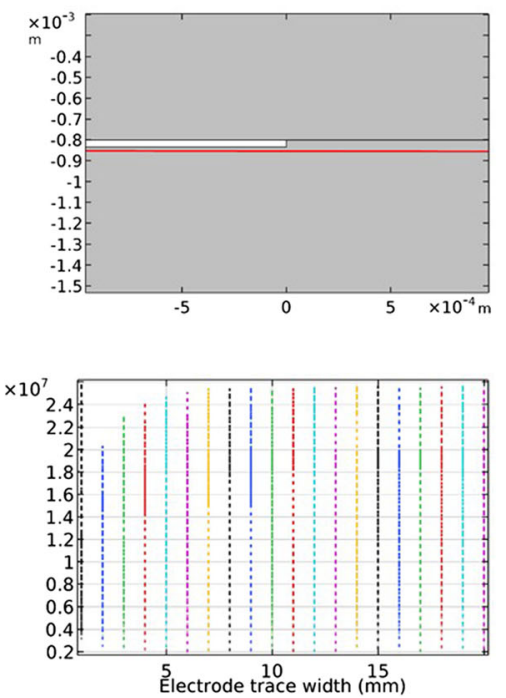

Fig. 2 Electric field simulations between edges of adjacent electrodes (left column), at the center of an electrode towards the opposite side of the dielectric (middle column), and tangential across the edge of an electrode (right column) with graphical representations of the lines of analysis for the parameter study (top row) and resulting field strengths over simulated trace widths (bottom row) 


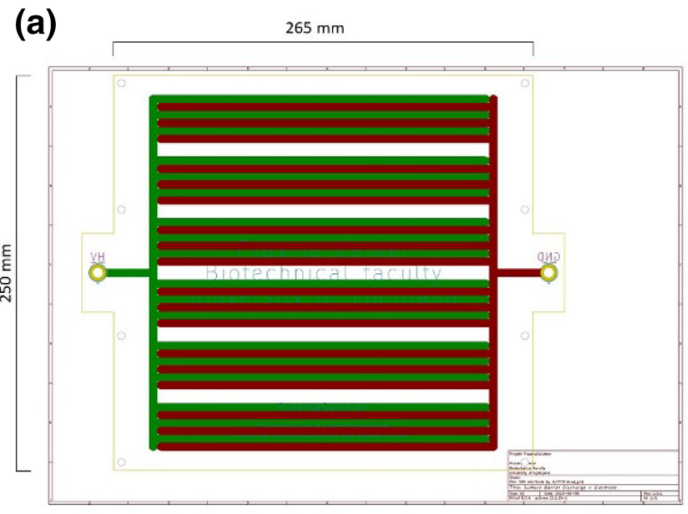

(b)

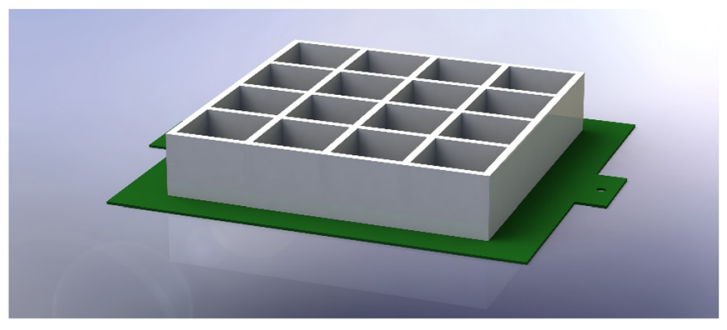

(c)

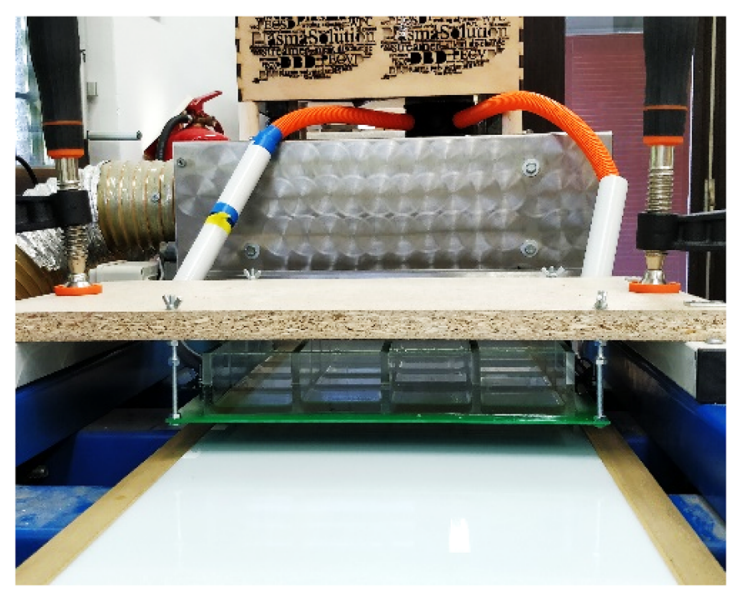

Fig. 3 Electrode design in KiCAD (a) and SolidWorks (b), and setup mounted over a conveyor belt (c)

between edges of adjacent electrodes (left column) until $5 \mathrm{~mm}$ trace width, whereas it remained approx. on the same value for further increased widths. The electric field strength tangential across the electrode edges (right column) represents the most important value, as this is the location of plasma ignition. The simulation shows a distinct increase until approx.
$8 \mathrm{~mm}$ trace width, whereas it remain similar for further increased widths. In comparison, the maximum electric field strength at the edge of a $5 \mathrm{~mm}$ wide trace shows a ca. $20 \%$ increase over the corresponding value at $2 \mathrm{~mm}$ width. Further increasing the width from $5 \mathrm{~mm}$ increased the field strength by no more than $5 \%$. The electric field strengths through the dielectric substrate at the center of an electrode (middle column) trace show a hyperbolic decrease with increasing trace widths, because the corresponding distance to the opposite electrode increases proportionally with the trace width. At $5 \mathrm{~mm}$ trace width, the maximum value of the electric field strength amounts to approx. $1 / 3^{\text {rd }}$ of the corresponding maximum at $1 \mathrm{~mm}$ trace width, thus indicating a proportional reduction in electric loss density within the dielectric material.

Based on the simulation results, the electrodes were designed with $5 \mathrm{~mm}$ wide traces in alternating stripes on both sides of the PCB. This layout leads to lines of plasma discharge at the trace edges with gaps centered over the traces, thus allowing for a large degree of electrode oxidation before failure. The electrode design was tested by small-scale electrodes with 3 pairs of $125 \mathrm{~mm}$ long traces on a $90 \mathrm{~mm} \times 150 \mathrm{~mm}$ PCB.

The treatments were carried out using up-scaled electrodes with 6 interconnected sets of 3 pairs of $205 \mathrm{~mm}$ long traces on a $250 \mathrm{~mm} \times 265 \mathrm{~mm}$ PCB, where the sets are spaced $10 \mathrm{~mm}$ apart (see Fig. 3a). The treatment of surfaces requires the positioning of such electrodes close to the specimens' surfaces, typically below a millimeter. In order to ensure a proper gap distance over the whole size, these larger PCB sizes were stabilized by attaching a grid of polymer plates on top (see Fig. 3b), which were glued to the electrode plate using a two-component epoxy adhesive (UHU PLUS schnellfest, UHU GmbH \& Co. KG, Bühl/Baden, Germany). These plates were further acting as a reservoir for an oil filling (Diesel motor oil 15W40 extra, Petrol d.d., Ljubljana, Slovenia), which prevented the plasma ignition on the upper side facing away from the specimen and acted as heat buffer to stabilize the temperature of the plasma system (see Fig. 3c).

High-voltage (HV) generation

The ignition of the plasma discharge requires electrical field strengths to exceed the breakthrough voltage 
$V_{b}$ of the working gas at pressure $p$ and discharge distance $d$, which in this case is given by the Paschen curve for air (Husain and Nema 1982):

$V_{b}=\frac{2737.5^{V} / \mathrm{kPa} \cdot \mathrm{cm} \cdot p \cdot d}{\ln (p \cdot d) \cdot 4.6295}$

For the used electrode geometry, stable plasma ignition occurs at voltages higher than approx. $8 \mathrm{kV}$. The generation of high voltage for such plasma applications often focus on the most energy-efficient converter technologies such as zero-voltage switching converters (Lee et al. 2003; Han et al. 2008; Mishima et al. 2009; Zin et al. 2017), which adapt switching frequencies to the primary LC (inductor-capacitor) circuit, thus reducing switching losses, and design the secondary side to a closely matching resonance (Harry 2010). However, the appearance and characteristics of DBDs in general and of SBDs specifically strongly depend on the excitation frequency and the shape of the signal. In particular, most effective plasma treatments in terms of their physicochemical outcomes are ignited using short $\mathrm{HV}$ pulses in the microsecond or even nanosecond timescale (Hirschberg et al. 2013). However, such short pulses can only be implemented if the resonant oscillations of the secondary (i.e. HV) LC circuit are attenuated, which consumes high proportions of the transferred energy and accordingly increases the electrical losses. Therefore, some solutions make use of the HV self-oscillations through periodical re-excitations after the oscillations declined to a defined fraction of the initial amplitude (Kuchenbecker et al. 2009).

The equipment presented in this publication uses a simple Flyback circuit with pulse-width modulation (PWM) waveform generator (c.f. Fajar et al. 2020) to generate the $\mathrm{HV}$ power output required for the plasma ignition. Fig. S1.1 in the supplemental materials shows the circuit schematics (left image) and the printed circuit board (PCB) layout (right image). This provides a robust, cost-efficient, and well-controlled solution to provide high voltages at a broad range of frequencies and with sufficient power to operate a plasma device. Self-resonant or self-switching circuits (Law and Anghel 2012; Fajar et al. 2020) would need to be optimized to different frequencies on different electrodes, and would thus become a more complex solution for this application. A commercial N-channel power MOSFET (Infineon CoolMOS C7 IPW60) is used to switch a Flyback transformer (TRANSHF_15KVAC, Voltagezone Electronics e.U., Graz, Austria). The primary side of the circuit is driven at low voltages up to $24 \mathrm{~V}$, but a failure of the plasma to ignite can cause resonant oscillations of the $\mathrm{HV}$ circuit, which may lead to an excessive overvoltage on the primary side. Thus, a high voltage power MOSFET with hard switching capability was selected, which is capable of pulse currents well above $100 \mathrm{~A}$. The MOSFET gate is driven through bulk junction transistors instead of an integrated circuit driver module to increase the circuit's robustness. Further safety features include resistors limiting the gate currents, Zener diodes preventing gate overvoltage on all transistors, and a power diode in parallel to the MOSFET's body diode. The energy efficiency can be optimized to the chosen frequency of operation by including tank (primary side) and buffer (secondary side) capacitors with the Flyback transformer to adjust the resonances. All design files for the used circuit are available (see data statement), including the exported GERBER files for manufacturing the printed circuit board.

Displayed in fig. S1.2 in the supplemental materials is the schematic wiring of the HV power supply. The power supply utilizes an LED driver (S-240-24, Mean Well Europe B.V., Amstelveen, The Netherlands) $24 \mathrm{~V}$ switch-mode power supply (SMPS) and a simple voltage control module (RD DPS5020-USB/BT,

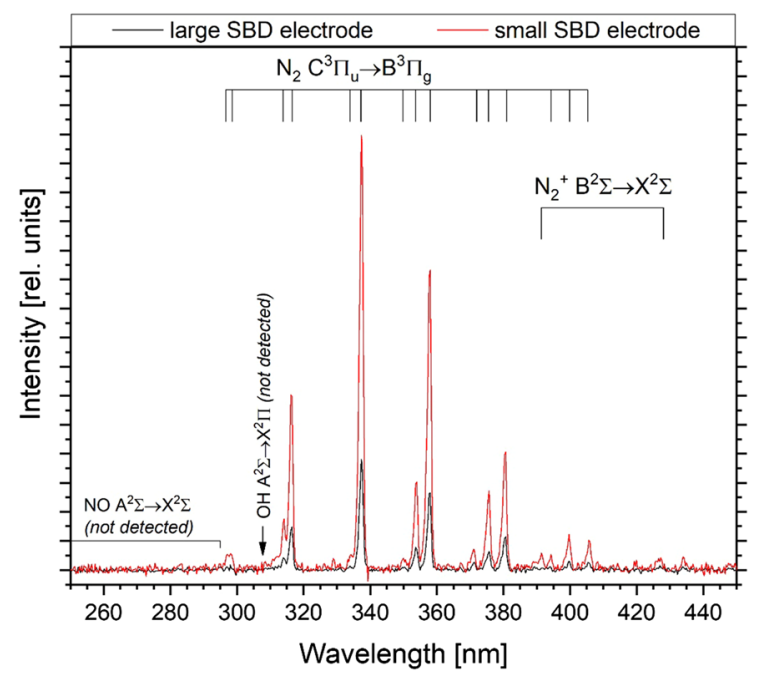

Fig. 4 OES spectra of the discharges on the large (black line) and the small SBD electrode (red line) in air 
Hangzhou Ruideng Technology Co., Ltd, Zhejiang,China) to supply the Flyback module. An integrated PWM signal generator (XY-PWM, XYKPWM or XY-LPWM; Eshinede Technology Shenzhen, China) is used to include control over the plasma ignition frequency and to adjust the duty cycle to the magnetic saturation of the Flyback transformer. A self-holding contactor latch (ESB 24-31, ABB Ltd., Zürich, Switzerland) is included as an additional safety feature. The $12 \mathrm{~V}$ and $5 \mathrm{~V}$ potentials are obtained from linear voltage regulator ICs L7812CV and L7805CV (STMicroelectronics N.V., Geneva, Switzerland), respectively. Furthermore, a small oscilloscope module (DSO138 mini, JYE Tech Ltd., Guilin, Guangxi, China) with the probe tip capacitively coupled to the transformer core can provide a meaningful diagnostic tool, which can be calibrated to measure the output voltage. All details on the power supply design are published online in the article's dataset (see data statement).

\section{Plasma characterization}

The plasma discharges were characterized using OES, as shown in Fig. 4. Both spectra show similar features, albeit at a slightly lower intensity for the larger electrode, as the input electrical charge and energy from the HV generator are distributed on a larger capacitor over a larger electrode area correspondingly over a larger plasma volume than for the smaller electrode design. Both spectra show features from the second positive system (SPS) of the neutral nitrogen molecule $\left(\mathrm{N}_{2} \mathrm{C}^{3} \Pi_{\mathrm{u}} \rightarrow \mathrm{B}^{3} \Pi_{\mathrm{g}}\right)$ (Országh et al. 2012) and from the first negative system (FNS) of the positive nitrogen molecule ion $\left(\mathrm{N}_{2}{ }^{+} \mathrm{B}^{2} \Sigma_{\mathrm{u}}{ }^{+} \rightarrow \mathrm{X}^{2-}\right.$ $\Sigma_{\mathrm{g}}{ }^{+}$) (Elkholy et al. 2018). Neither hydroxyl radicals $\left(\mathrm{OH} \mathrm{A} \Sigma^{2} \rightarrow \mathrm{X}^{2} \Pi\right.$ ) (Mizeraczyk et al. 2012) nor nitrous oxides (NO $\mathrm{A}^{2} \Sigma^{+} \rightarrow \mathrm{X}^{2} \Sigma$ ) were detected (Xiao et al. 2014) at measurable concentrations with the used setup. Further, no significant intensities of atomic oxygen or nitrogen, nor the first positive system (FPS) of the neutral nitrogen molecule $\left(\mathrm{N}_{2}\right.$ $\left.\mathrm{B}^{3} \Pi_{\mathrm{g}} \rightarrow \mathrm{A}^{3} \Sigma_{\mathrm{u}}{ }^{+}\right)$were possible to detect at sufficient intensity in the measured spectra. Here it should be mentioned that even though there is no emission from $\mathrm{OH}, \mathrm{NO}, \mathrm{O}$ and $\mathrm{N}$ visible on OES spectra, it does not necessarily mean that there are no $\mathrm{OH}$, NO molecules or no $\mathrm{N}$ or $\mathrm{O}$ atoms. These species may be present in plasma, but either low concentrations or electrons do not have enough energy to excite these species to higher energy levels. The evaluation from the intensity ratio of the lines at $391.4 \mathrm{~nm}$ and $394.3 \mathrm{~nm}$ according to Paris and colleagues (Paris et al. 2005, 2006; Pancheshnyi 2006; Kuchenbecker et al. 2009) as described in the "Materials and methods" section yielded reduced electric field strengths of $556 \mathrm{Td}$ for the small SBD electrode and $444 \mathrm{Td}$ for the larger SBD electrode. Through Bolsig + (Hagelaar and Pitchford 2005; Pitchford 2013), these amounted to mean electron energies of $10.8 \mathrm{eV}$ and $9.1 \mathrm{eV}$, respectively. The detailed analysis including $\mathrm{E} / \mathrm{N}$

Table 3 Cracking assessment on different coated and plasma pretreated sample systems after 6 and 10 months of natural weathering

\begin{tabular}{|l|l|l|l|}
\hline \multirow{2}{*}{ Surface finish } & Plasma & $\mathbf{6}$ months & $\mathbf{1 0 ~ m o n t h s}$ \\
\hline \multirow{3}{*}{ Uncoated } & Yes & 0 & 0 \\
\cline { 2 - 4 } & No & 0 & 0 \\
\hline \multirow{3}{*}{ Wang oil } & Yes & 0 & 0 \\
\cline { 2 - 4 } & No & 0 & $1.3 \mathrm{~S} 1.3 \mathrm{a}$ \\
\hline \multirow{3}{*}{ Solvent-based UV stain } & Yes & 0 & $0.7 \mathrm{~S} 0.7 \mathrm{a}$ \\
\cline { 2 - 4 } & No & $1.3 \mathrm{~S} 2.3 \mathrm{a}$ & $3 \mathrm{~S} 3.7 \mathrm{~b}$ \\
\hline & Yes & 0 & 0 \\
\cline { 2 - 4 } & No & $1.7 \mathrm{~S} 2.7 \mathrm{~b}$ & $3.7 \mathrm{S3.7} \mathrm{b}$ \\
\hline
\end{tabular}


calculations and Bolsig + simulation results are provided in the published dataset (see data statement).

In a comparable coplanar surface discharge, Peters et al. (2018) found electron energies of about $12 \mathrm{eV}$ (Peters et al. 2018), which are higher than the ones found in the present study to the short $(27 \mu \mathrm{s})$ high voltage pulses with higher peak voltages (19-29 kV) used by Peters. Translational temperatures of a comparable surface discharge were found by Peters et al. in the range of 333-367 K depending on substrate and treatment time, rotational temperatures in the range of $315-440 \mathrm{~K}$ and vibrational temperatures around $2400 \mathrm{~K}$ (Peters et al. 2017). In this study, however, the lower electron energies and the lower electrical power input are expected to deliver slightly lower gas temperatures. Moreover, due to the integrated surface discharge in this study as opposed to the coplanar discharge used by Peters et al., a lower impact of the substrate can be expected.

\section{Results and discussion}

During the outdoor exposure, the specimens with various coating systems were thoroughly inspected and evaluated after one month, three months, six months and finally, at the end, after ten months of exposure. Visual evaluations were repeated with the help of collected photographs of scanned samples at the end of the experiment.

\section{Visual evaluation of the aged samples}

According to EN ISO 4628, the visual evaluation was focused on blistering, cracking, peeling, chalking, and the extent of biotic infections and mold. Despite almost one year of exposure, no bubbling, peeling, and chalking of the coating film was observed on the surface of the samples; these factors were therefore excluded from the analysis. Most specimens presented cracked and infected films and consequently stained surfaces due to the influence of biotic factors, such as fungi or mold. Cracks in the coating films first appeared on the samples only six months after exposure and then escalated further, as shown in Table 3. The most intense cracking was observed on specimens with solvent-based UV stain applied without plasma pretreatment (BB-030-bp), where larger cracks are extending through the entire coating (a)

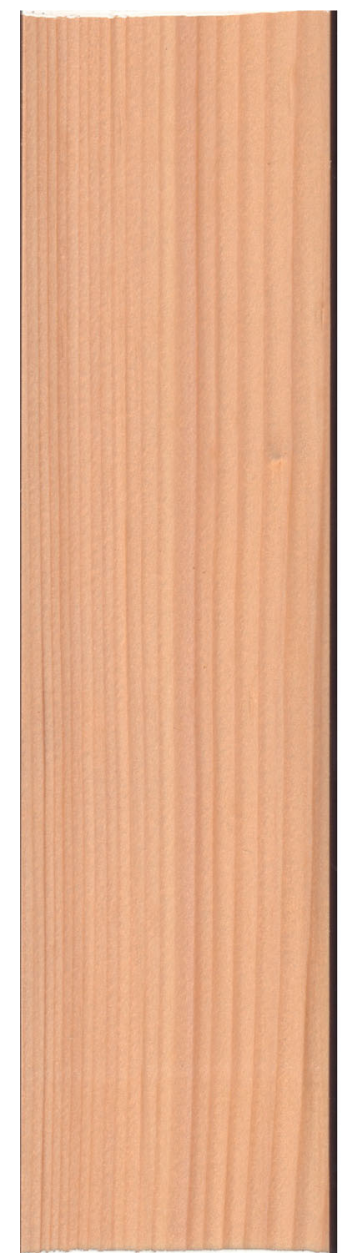

(b)

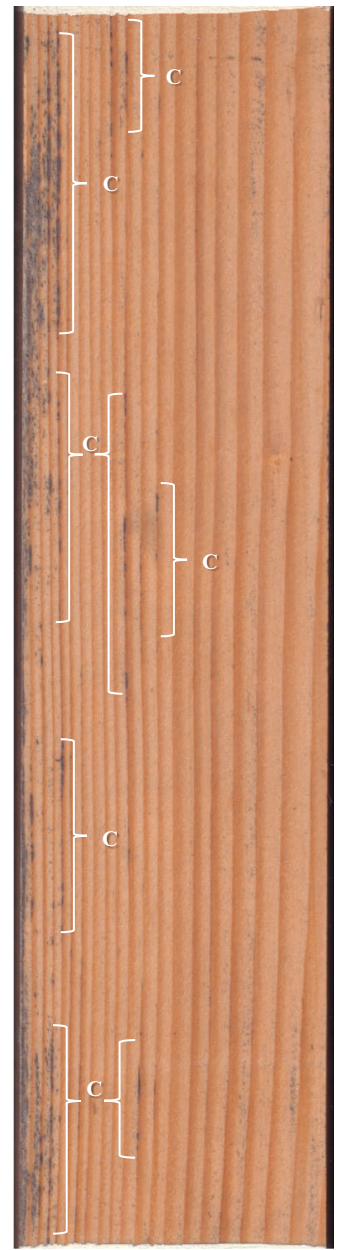

Fig. 5 Comparison of an exemplary specimen (BB-030-bp) as prepared (a) and after outdoor exposure exhibiting strong cracking (C-cracked area) and significant infections with biotic factors (b)

system. For specimens BB-032-bp, and for the water-based stain applied without plasma, EB-023bp and EB-024-bp, only the top layer of the coating was affected, whereas the bottom layer remained intact. Very small, barely visible cracks also appeared on untreated samples of tung oil (blue field, Table 3). In comparison with untreated samples, the degree of cracking on plasma-pretreated specimens was significantly reduced. Only one plasma-pretreated specimen exhibited cracks (EB-020-p), albeit to a minimal degree. This positive effect of plasma pretreatments might be attributed to the enhanced wetting and deeper 
Table 4 Estimation of the extent of infections with biotic factors on different coated and plasma pretreated sample systems after 1, 3, 6 , and 10 months of natural weathering

\begin{tabular}{|l|l|l|l|l|l|}
\hline Coating & Plasma & $\mathbf{1}$ month & $\mathbf{3}$ months & $\mathbf{6}$ months & $\mathbf{1 0}$ months \\
\hline \multirow{3}{*}{ Uncoated } & Yes & $1 / 1 / 1$ & $1 / 1 / 1$ & $2.3 / 3 / 2$ & $3 / 3 / 3$ \\
\cline { 2 - 6 } & No & $1.3 / 1 / 1$ & $2 / 1.3 / 1.3$ & $3 / 2 / 2$ & $3 / 2.3 / 2.3$ \\
\hline \multirow{3}{*}{ Tung oil } & Yes & $1 / 1 / 1.3$ & $2 / 1 / 2$ & $3 / 2.3 / 1.7$ & $3 / 2.7 / 2.7$ \\
\cline { 2 - 6 } & No & $1 / 1 / 1$ & $2 / 1.3 / 1$ & $3 / 3 / 2$ & $4 / 4 / 4$ \\
\hline \multirow{3}{*}{ Water-based stain } & Yes & 0 & $1 / 1 / 1$ & $2 / 1 / 1$ & $3 / 2 / 1$ \\
\hline \multirow{3}{*}{ Solvent-based UV stain } & No & 0 & $1 / 1 / 1$ & $1.7 / 1 / 1$ & $4 / 3 / 2$ \\
\cline { 2 - 6 } & Yes & 0 & $1 / 1 / 1$ & $2 / 1.3 / 1$ & $2.7 / 2 / 1.7$ \\
\cline { 2 - 6 } & No & 0 & $1 / 1 / 1$ & $2.3 / 2.3 / 1.3$ & $3.7 / 3 / 2$ \\
\hline
\end{tabular}

penetration of coatings into the wood surfaces, which has been reported before (Žigon et al. 2020b). This prolongs the time after which cracks appear on the wood and reduces the depth of cracks, which in turn reduces the possibility of wood decay due to infection with biotic decomposition factors. An example of strong cracking after exposure and the as-prepared specimen for comparison are presented in Fig. 5a, b, respectively.

The extent of infections with biotic factors according to EN ISO 4628-1:2003 on the exposed specimens were estimated in comparison to control specimen, which were stored in a conditioned dark room during the entire time of the outdoor exposure experiments. The individual assessments in Table 4 show an increasing extent of infections with longer exposure periods. After ten months of exposure, biotic factors had strongly impaired a large fraction of samples. The worst conditions were found for untreated specimens coated with tung oil. This likely originates in the poorer resistance of wood coatings based on natural ingredients compared to water-based and organic solvent-based coatings. Samples with an extent of infections with biotic factors, that would require maintenance or replacement (moderate to significant, very visible infections), are marked in red. The first minimal infections are highlighted in blue in Table 4 . On the surface of uncoated exposed samples and samples coated with tung oil, first infections appeared one month after the start of the exposure. Infections on specimens finished with the water-based and with the solvent-based UV stain surface systems were first observed only three months after start of the outdoor exposure, indicating the better resistance of these systems to the attack of biotic factors. In comparison to the untreated specimens, the plasma pretreatments yielded slightly lower values of infection prevalence over the entire periods of exposure. This again indicates the positive effect of plasma on coated wood surfaces, which, by inhibiting infections, could prolong the usefulness of outdoor wood products and reduce their decay. An example of high extent of infections with biotic factors of the specimen before and after exposure for comparison are presented in Fig. 5a, b, respectively.

\section{Gloss and color changes}

The unexposed specimens with cured surface systems showed the highest surface gloss for the solvent-based UV stain (values between 50.2 and 58.2), followed by the water-based stain (19.8 to 22.7), and tung oil (6.7 to 7.2), whereas uncoated specimens exhibited the lowest surface gloss (approx. 5.5). No impact of plasma pretreatments on the surface gloss was observed prior to the outdoor exposure.

The gloss change during the outdoor weathering is presented in Table 5. The strongest pronounced loss of gloss during six months of outdoor weathering was observed for the solvent-based UV stain (blue markings). The values decreased from 59.0 to 25.8 for the plasma-pretreated specimens and from 48.1 to 20.8 for 
Table 5 Evaluation of the gloss change on different coated and plasma pretreated sample systems with and without exposure to natural weathering after $1,3,6$, and 10 months

\begin{tabular}{|c|c|c|c|c|c|}
\hline Coating & Plasma & Weathered & 1 month & 3 months & 6 months \\
\hline \multirow{4}{*}{ Uncoated } & \multirow{2}{*}{ Yes } & No & 0.1 & 0.1 & 0.1 \\
\hline & & Yes & 0.6 & 1.2 & 0.3 \\
\hline & \multirow{2}{*}{ No } & No & 0.0 & 0.1 & 0.1 \\
\hline & & Yes & 1.0 & 1.6 & 0.6 \\
\hline \multirow{4}{*}{ Tung oil } & \multirow{2}{*}{ Yes } & No & -0.1 & -0.4 & -0.5 \\
\hline & & Yes & -2.2 & -3.0 & -3.5 \\
\hline & \multirow{2}{*}{ No } & No & 0.0 & -0.1 & 0.2 \\
\hline & & Yes & -3.3 & -4.0 & -4.6 \\
\hline \multirow{4}{*}{ Water-based stain } & \multirow{2}{*}{ Yes } & No & 0.6 & 0.1 & 0.0 \\
\hline & & Yes & 0.7 & -0.1 & -3.4 \\
\hline & \multirow{2}{*}{ No } & No & 1.2 & 1.9 & -0.2 \\
\hline & & Yes & 1.6 & 0.5 & -4.4 \\
\hline \multirow{4}{*}{ Solvent-based UV stain } & \multirow{2}{*}{ Yes } & No & -6.2 & -6.2 & -5.6 \\
\hline & & Yes & -16.4 & -19.7 & -33.2 \\
\hline & \multirow{2}{*}{ No } & No & -4.2 & -6.0 & -6.0 \\
\hline & & Yes & -15.1 & -18.4 & -27.3 \\
\hline
\end{tabular}

the untreated specimens. Both are drastic decreases of the surface gloss, with no significant impact of the plasma pretreatment. The lowest gloss values during and after outdoor weathering were obtained for uncoated samples, again. Reference samples stored in the dark showed greatly reduced surface gloss changes, indicating the gloss change to be mainly induced as an effect of the outdoor weathering, i.e. through weather, biotic factors, and UV radiation.

In a comparison of plasma-pretreated and untreated specimens, the response of plasma-pretreated surfaces was on average, slightly better for the uncoated, tung oil, and water-based stain samples. However, the recorded values are within the normal standard deviation, thus not providing a statistically significant plasma treatment impact on these surface systems.

The findings for the solvent-based UV stain coating system, however, were different, showing a notable decrease in gloss already in the reference samples stored in dark, which can be attributed to the properties and composition of the coating (wax content, UV filters, absorbers, free radical scavengers) and the internal aging process of the cured film itself. Moreover, gloss changes were slightly larger on plasma-pretreated specimens than untreated specimens, albeit statistically insignificant. However, this might well be related to the creation of radicals on the wood surface by the plasma known from previous studies (Setoyama 1996), which could reduce the amount of radical scavengers present in the UV-protective stain.

The initial color of the different coating systems amounted to $L * / a * / b^{*}$ values of $79.5 / 5.9 / 22.4$ and 78.1/6.2/22.6 for the uncoated plasma-treated and untreated specimens, respectively, of 74.8/8.1/28.4 and 74.8/8.3/29.8 for the plasma-treated and untreated Tung oil specimens, respectively, of 77.7/5.5/27.3 and 77.6/5.5/27.2 for the plasma-treated and untreated water-based stain, respectively, as well as of 76.8/6.8/ 33.0 and 74.6/7.6/31.8 for the plasma-treated and untreated solvent-based UV stain, respectively. All surface systems impose changes to the color of the specimens, with a slight darkening that was most 
Table 6 Evaluation of the color change on different coated and plasma pretreated sample systems after 10 months with and without exposure to natural weathering

\begin{tabular}{|c|c|c|c|c|c|c|}
\hline \multirow[t]{2}{*}{ Coating } & \multirow[t]{2}{*}{ Plasma } & \multirow[t]{2}{*}{ Weathered } & \multicolumn{4}{|l|}{ Change } \\
\hline & & & $\Delta L^{*}$ & $\Delta a^{*}$ & $\Delta b^{*}$ & $\Delta E^{*}$ \\
\hline \multirow[t]{4}{*}{ Uncoated } & \multirow[t]{2}{*}{ Yes } & No & -0.2 & -0.5 & -0.4 & 0.7 \\
\hline & & Yes & -26.1 & -3.1 & -14.4 & 30.0 \\
\hline & \multirow[t]{2}{*}{ No } & No & -0.1 & -0.5 & -0.4 & 0.6 \\
\hline & & Yes & -26.4 & -3.6 & -14.9 & 30.6 \\
\hline \multirow[t]{4}{*}{ Tung oil } & \multirow[t]{2}{*}{ Yes } & No & -0.5 & -0.3 & 3.5 & 3.5 \\
\hline & & Yes & -27.4 & -1.0 & -10.1 & 29.2 \\
\hline & \multirow[t]{2}{*}{ No } & No & 0.1 & -0.8 & 2.7 & 2.8 \\
\hline & & Yes & -25.5 & -0.5 & -8.0 & 26.8 \\
\hline \multirow[t]{4}{*}{ Water-based stain } & \multirow[t]{2}{*}{ Yes } & No & -0.3 & -0.1 & 0.2 & 0.4 \\
\hline & & Yes & -9.8 & 1.9 & -2.0 & 10.2 \\
\hline & \multirow[t]{2}{*}{ No } & No & -0.4 & 0.0 & 0.2 & 0.4 \\
\hline & & Yes & -9.4 & 2.0 & -1.4 & 9.7 \\
\hline \multirow[t]{4}{*}{ Solvent-based UV stain } & \multirow[t]{2}{*}{ Yes } & No & -0.3 & 0.7 & 2.4 & 2.5 \\
\hline & & Yes & -9.5 & 3.6 & -2.2 & 10.4 \\
\hline & \multirow[t]{2}{*}{ No } & No & -0.6 & 0.5 & 2.4 & 2.5 \\
\hline & & Yes & -7.5 & 2.4 & -1.7 & 8.3 \\
\hline
\end{tabular}

pronounced on the Tung oil. Further, most of the surfaces took on a slightly reddish-yellow hue, as the $a^{*}$ and $b^{*}$ values increase after coating application except for the water-based stain, which resulted in a more green-yellow color on the surface.

In the first few months, the color change was most pronounced on the uncoated specimens and on the Tung oil samples. The color and gloss data over the entire weathering period in published in the article's dataset (see data statement). Table 6 presents the averaged color change for all surface systems after ten months of outdoor weathering compared to the corresponding reference samples stored in the dark. As expected, the color changes in non-exposed samples are significantly lower than the changes in outdoor aged samples. This is typical for outdoor weathering since photodegradation as a result of UV radiation from sunlight usually has the strongest impact on surface discoloration and wood color changes due to photo-induced breakdown of chemical constituents in wood, especially in lignin (Pandey 2005; Srinivasa and Pandey 2012). However, color changes were also noticeable on samples stored in the dark at the time of the outdoor exposure. These are likely related to internal aging processes within the coating systems depending on the composition, such as e.g. yellowing of polyurethane-based varnishes is known (Rosu et al. 2009; Rossi et al. 2016).

The plasma pretreatment did not have a significant effect on the non-weathered specimens; neither did it influence the color change of the uncoated samples. For the specimens exposed to outdoor weathering, a slightly stronger color change is visible for plasmapretreated samples, particularly in the luminance $L^{*}$ and towards the blue end of the $b^{*}$ parameter, indicating dominance of lignin and holocellulose decomposition (Geffertová et al. 2018). For the stains, this is less pronounced on the water-based stain, but particularly strongly pronounced on the UV-protective solvent-based stain. This might be related to the effects of plasma treatments on wood to remove volatile organic compounds that otherwise might act as radical scavengers to mitigate UV damage, while the plasma further induces surface radical groups, paving the way for the UV degradation of the material.

Adhesion strength determined by cross-cutting

The adhesion strength of the two film-forming surface systems (SIST EN ISO 2409:1997) was measured immediately after the end of the outdoor weathering test, i.e. after ten months of outdoor exposure. As 
Table 7 Adhesion strength determination by crosscut testing of different coated and plasma pretreated sample systems after 10 months with and without exposure to natural weathering

\begin{tabular}{|l|l|l|l|l|}
\hline \multirow{4}{*}{ Coating } & Plasma & Weathered & Blade spacing 2 mm & Blade spacing 1 mm \\
\hline \multirow{3}{*}{ Water-based stain } & \multirow{3}{*}{ Yes } & No & 1 & 1 \\
\cline { 3 - 5 } & & Yes & 0.8 & 1.8 \\
\cline { 2 - 5 } & \multirow{3}{*}{ No } & No & 0 & 1 \\
\cline { 3 - 5 } & \multirow{3}{*}{ Solvent-based UV stain } & Yes & 1 & 2.8 \\
\hline \multirow{3}{*}{ Yes } & \multirow{2}{*}{ No } & Yes & 1 & 1 \\
\cline { 3 - 5 } & & No & 1 & 2.3 \\
\cline { 3 - 5 } & & Yes & 1.3 & 1 \\
\hline
\end{tabular}

presented in Table 7, both the water-based and the solvent-based UV stain displayed good adhesion performance. At a blade spacing of $2 \mathrm{~mm}$, the scores averaged all-around a value of 1 . The same values were obtained on the non-weathered reference specimens. After weathering and at a knife spacing of $1 \mathrm{~mm}$, the solvent-based coating, plasma-pretreated specimens averaged a score of 2.3 as compared to the corresponding non-pretreated samples with a score of 2.7. Differences were more pronounced with the water-borne stain, yielding averaged scores of 1.8 for the plasma-pretreated substrates as compared to 2.8 for the non-pretreated specimens. Again, the differences between plasma-pretreated and non-pretreated specimens is likely a result of the reduced crack formation and hence a reduced degradation of the interface between substrate and coating due to weathering.

Particularly for the UV-protective coating, the effect was less pronounced than for the water-based stain. This might be related to the impact of the plasma modification modifying the substrates' surface free energy towards hydrophilic behaviors, thus yielding a stronger effect for water-based coating systems (Žigon et al. 2018). However, this might also be related to the interference of plasma-induced chemical groups on the wood surfaces interfering with the stain composition.

\section{Conclusions}

Plasma discharges are interesting tools for surface modifications, and they can be implemented with simple means and small budgets. The development of a surface barrier discharge (SBD) as an atmospheric pressure plasma device has been successfully demonstrated and the design and construction files have been made openly available to allow a more wide-spread access to this technology. The effectiveness and the energy efficiency are lower than with commercial and industrial plasma treatment equipment, however, the performance of the simplified device was shown to provide worthwhile effects for widespread applications.

The SBD plasma was further utilized as a pretreatment before coating application on wooden specimens for outdoor usage. After coating application, the initial colors were not impacted by the plasma pretreatments, whereas a slightly increased color loss was observed for the plasma-pretreated specimens, albeit of little statistical significance. This effect was discussed as likely related to the removal of volatile organic compounds from and the generation of radical chemical groups on the wood surfaces known from reference literature. In contrast to these effects, the plasma-pretreated specimens exhibited strongly reduced cracking after exposure to outdoor weathering. The reduction or absence of cracks is the likely origin of further positive observations. The plasmapretreated specimens were significantly less prone to infections with biotic factors and showed an improved 
adhesion performance of the coatings in cross-cut tests after ten months of outdoor weathering.

In comparison, the advantages obtained by the plasma pretreatments were much stronger pronounced for water-based coatings in comparison to solventbased ones. Moreover, UV-protective properties of both stains and oils appeared impacted by the plasma pretreatments. This indicates a meaningful application of plasma treatments as pretreatments for water-based coatings, whereas UV-protective functionalities should not be included in direct contact with the plasma-functionalized interface.

Acknowledgments The authors acknowledge the financial support from the Slovenian Research Agency (research program funding No. P4-0015, "Wood and lignocellulose composites"). This project has received funding from the European Union's Horizon 2020 research and innovation programme under grant agreement No 745936. A CC BY or equivalent license is applied to the Author Accepted Manuscript arising from this submission, in accordance with the grant's open access conditions.

Authors' contributions SD Funding acquisition, Project administration, Conceptualization, Methodology, Supervision, Investigation, Formal analysis, Data curation, Visualization, Writing - original draft. MP Investigation, Formal analysis, Visualization, Writing — original draft. JŽ Resources, Writingreview and editing. RZ Investigation, Resources, Writingreview and editing. MP Funding acquisition, Conceptualization, Supervision, Resources, Writing-review and editing. MP Conceptualization, Methodology, Formal analysis, Supervision, Writing-review and editing.

Funding This research has received financial support from the Slovenian Research Agency under research program funding No. P4-0015, "Wood and lignocellulose composites". This project has received funding from the European Union's Horizon 2020 research and innovation programme under grant agreement No 745936. A CC BY or equivalent license is applied to the Author Accepted Manuscript arising from this submission, in accordance with the grant's open access conditions.

Availability of data and material The entire dataset was published on Zenodo via https://doi.org/10.5281/zenodo. 4133809 , including the electrode design and the power supply design, as well as all raw and analyzed data for the application on wood.

\section{Code availability Not applicable.}

\section{Declarations}

Conflict of interest The authors declare no conflict of interest, and the manuscript is approved by all authors. We confirm that neither the manuscript nor any parts of its content are currently under consideration or published in another journal.

Ethics approval Not applicable.

Open Access This article is licensed under a Creative Commons Attribution 4.0 International License, which permits use, sharing, adaptation, distribution and reproduction in any medium or format, as long as you give appropriate credit to the original author(s) and the source, provide a link to the Creative Commons licence, and indicate if changes were made. The images or other third party material in this article are included in the article's Creative Commons licence, unless indicated otherwise in a credit line to the material. If material is not included in the article's Creative Commons licence and your intended use is not permitted by statutory regulation or exceeds the permitted use, you will need to obtain permission directly from the copyright holder. To view a copy of this licence, visit http://creativecommons.org/licenses/by/4.0/.

\section{References}

Akamatsu H (2014) Generation of line-shaped atmospheric pressure plasma on planar surface with diffuse coplanar surface barrier discharge. J Phys Conf Ser 518:012015. https://doi.org/10.1088/1742-6596/518/1/012015

Avramidis G, Tebbe B, Nothnick E, Militz H, Viöl W, Wolkenhauer A (2010) Wood veneer modification by atmospheric pressure plasma treatment for improved absorption characteristics. In: Proceedings of the fifth European conference on wood modification. Riga, Latvia, pp 365-373

Bialski A, Manley RJ, Wertheimer MR, Schreiber HP (1975) Composite materials with plasma-treated components: treatment-property correlation. Polym Prepr 16:70-72

Bonaventura Z, Bourdon A, Celestin S, Pasko VP (2011) Electric field determination in streamer discharges in air at atmospheric pressure. Plasma Sources Sci Technol 20(3):035012. https://doi.org/10.1088/0963-0252/20/3/ 035012

Čech J, Brablec A, St'ahel P, Černák M (2007) Influence of electrode temperature on plasma parameters of diffuse coplanar surface discharge. In: 28th ICPIG, July 15-20, 2007, Prague, Czech Republic

Čech J, St'ahel P, Navrátil Z, Černák M (2008) Space and time resolved optical emission spectroscopy of diffuse surface coplanar barrier discharge in nitrogen. In: Chemické Listy, II Central European Symposium on Plasma Chemistry, vol 2008, No 102. pp s1348-s1351

Čech J, St'ahel P, Navrátil Z (2009) The influence of electrode gap width on plasma properties of diffuse coplanar surface barrier discharge in nitrogen. Eur Phys J D 54:259. https:// doi.org/10.1140/epjd/e2009-00013-1

Čech J, Zemánek M, Sahel P, Dvořáková H, Černák M (2014) Influence of substrate thickness on diffuse coplanar surface barrier discharge properties. Acta Polytech 54(6):383-388. https://doi.org/10.14311/AP.2014.54.0383 
Čech J, Hanusová J, St’ahel P, Černák M (2015) Diffuse Coplanar Surface Barrier Discharge in Artificial Air. Stat Behav Microdisch. https://doi.org/10.1515/chem-20150062

Čech J, Brablec A, Černák M, Puač N, Selaković N, Petrović ZLJ (2017) Mass spectrometry of diffuse coplanar surface barrier discharge: influence of discharge frequency and oxygen content in $\mathrm{N}_{2} / \mathrm{O}_{2}$ mixture. Eur Phys J D 71:27. https://doi.org/10.1140/epjd/e2016-70607-5

Černák M, Černáková L, Hudec I, Kováčik D, Zahoranová A (2009) Diffuse coplanar surface barrier discharge and its applications for in-line processing of low-added-value materials. Eur Phys J Appl Phys 47:22806. https://doi.org/ 10.1051/epjap/2009131

Černák M, Kováčik D, Ráhel' J, St'ahel P, Zahoranová A, Kubincová J, Tóth A, Černáková L (2011) Generation of a high-density highly non-equilibrium air plasma for highspeed large-area flat surface processing. Plasma Phys Control Fusion 53(12):124031. https://doi.org/10.1088/ 0741-3335/53/12/124031

Dedrick J, Boswell RW, Audier P, Rabat H, Hong D, Charles C (2011) Plasma propagation of a $13.56 \mathrm{MHz}$ asymmetric surface barrier discharge in atmospheric pressure air. J Phys D Appl Phys 44:205202. https://doi.org/10.1088/ 0022-3727/44/20/205202

Denes FS, Cruz-Barba LE, Manolache S (2005) Plasma treatment of wood. In: Rowell RM (ed) Handbook of wood chemistryand wood composites, 1st edn. CRC press, Boca Raton, pp 447-474. ISBN 978-0-429-20900-0. https://doi. org/10.1201/9780203492437

Dimitrakellis P, Zeniou A, Stratakos Y, Gogolides E (2016) Radio frequency atmospheric plasma source on a printed circuit board for large area, uniform processing of polymeric materials. Plasma Sources Sci Technol 25:025015. https://doi.org/10.1088/0963-0252/25/2/025015

Dimitrakellis P, Gogolides E, Zeniou A, Awsiuk K, Rysz J, Marzec MM (2017) Transition between stable hydrophilization and fast etching/hydrophilization of poly(methyl)methacrylate polymer using a novel atmospheric pressure dielectric barrier discharge source. J Vac Sci Technol A 35(4):041303. https://doi.org/10.1116/1. 4984613

ElectricityMap (2020) ElectricityMap live, Slovenia, October 22nd, 2020, 10:30. https://www.electricitymap.org/zone/ SI. Accessed 22 Oct 2020

Elkholy A, Nijdam S, van Veldhuizen E, DamN, van OijenJ, Ebert U, de Goey LPJ, (2018) Characteristics of a novel nanosecond DBD microplasma reactor for flow applications. Plasma Sources Sci Technol 27(5):055014. https:// doi.org/10.1088/1361-6595/aabf49

EN ISO 4628-4:1982, Paints and varnishes-evaluation of degradation of paint coatings - designation of intensity, quantity and size of common types of defect-part 4: Designation of degree of cracking

EN ISO 4628-1:2003, Paints and varnishes-evaluation of degradation of coatings - designation of quantity and size of defects, and of intensity of uniform changes in appearance-part 1: general introduction and designation system.

Fajar MI, Amalda EC, Syah MAA, Nurussaadah (2020) Design of a switching flyback transformer as high voltage and frequency power supply for raw milk cold plasma sterilization. Int J Sci Technol Manag 1(3):230-236. https://doi.org/10.46729/ijstm.v1i3.50

Fridman AA (2008) Plasma chemistry. Cambridge University Press, Cambridge. ISBN 978-0-521-84735-3

Geffertová J, Geffert A, Výbohová E (2018) The effect of UV irradiation on the colour change of the spruce wood. Acta Facultatis Xylologiae Zvolen 60:41-50. https://doi.org/10. 17423/afx.2018.60.1.05

Gerullis S, Kretzschmar BSM, Pfuch A, Beier O, Beyer M, Grünler B (2018) Influence of atmospheric pressure plasma jet and diffuse coplanar surface barrier discharge treatments on wood surface properties: a comparative study. Plasma Process Polym 15(10):1800058. https://doi.org/10. 1002/ppap.201800058

Gogolides E, Zeniou A, Dimitrakellis P (2016) Large area, uniform, atmospheric pressure plasma processing device, European Patent application EP 3142467 A1, filed 08.09.2016, published 15.03.2017

Golda J, Held J, Redeker B, Konkowski M, Beijer P, Sobota A, Kroesen G, Braithwaite NStJ, Reuter S, Turner MM, Gans T, O'Connell D, Schulz-von der Gathen V (2016) Concepts and characteristics of the "COST reference microplasma Jet.” J Phys D Appl Phys 49(8):084003. https://doi.org/10. 1088/0022-3727/49/8/084003

Golda J, Held J, Redeker B, Konkowski M, Beijer P, Sobota A, Kroesen G, Braithwaite NStJ, Reuter S, Turner MM, Gans T, O'Connell D, Schulz-von der Gathen V (2018) Corrigendum: concepts and characteristics of the 'COST Reference Microplasma Jet' (2016 J. Phys. D: Appl. Phys. 49 084003). J Phys D: Appl Phys 52(2):029503. https://doi. org/10.1088/1361-6463/aae8c8

Hagelaar GJM, Pitchford LC (2005) Solving the Boltzmann equation to obtain electron transport coefficients and rate coefficients for fluid models. Plasma Sources Sci Technol 14:722-733

Han SK, Kim TS, Moon GW, Youn MJ (2008) High efficiency active clamp forward converter for sustaining power module of plasma display panel. IEEE Trans Ind Electron 55(4):1874-1876. https://doi.org/10.1109/tie.2007.911208

Hansen L, Reck K, Kersten H (2019) Energy flux measurements on an atmospheric pressure surface barrier discharge. J Phys D Appl Phys 52:325201. https://doi.org/10.1088/ 1361-6463/ab216c

Harry JE (2010) Introduction to plasma technology: science, engineering, and applications. Wiley-VCH Verlag \& Co KGaA, Weinheim, Germany. ISBN 978-3-527-32763-8

Hill CAS (2007) Wood modification: chemical, thermal and other processes. Wiley, Hoboken, New Jersey, USA. ISBN 978-0-470-02173-6

Hirschberg J, Omairi T, Mertens N, Helmke A, Emmert S, Viöl W (2013) Influence of excitation pulse duration of dielectric barrier discharges on biomedical applications. J Phys D Appl Phys 46:165201. https://doi.org/10.1088/0022-3727/ 46/16/165201

Hoder T, Š́ra M, Kozlov KV, Wagner HE (2008) Investigation of the coplanar barrier discharge in synthetic air at atmospheric pressure by cross-correlation spectroscopy. J Phys D Appl Phys 41:035212. https://doi.org/10.1088/00223727/41/3/035212

Hoder T, Šíra M, Kozlov KV, Wagner HE (2009) CORRIGENDUM to Investigation of the coplanar barrier 
discharge in synthetic air at atmospheric pressure by crosscorrelation spectroscopy. J Phys D Appl Phys 42:049802. https://doi.org/10.1088/0022-3727/42/4/049802

Homola T, Matoušek J, Kormunda M, Wu LYL, Černák M (2013) Plasma treatment of glass surfaces using diffuse coplanar surface barrier discharge in ambient air. Plasma Chem Plasma Process 33:881-894. https://doi.org/10. 1007/s11090-013-9467-3

Husain E, Nema RS (1982) Analysis of Paschen curves for air, $\mathrm{N} 2$ and SF6 using the townsend breakdown equation. IEEE Trans Electr Insul EI 17(4):350-353. https://doi.org/10. 1109/tei.1982.298506

ISO/DIS 7724-2:1997, Paints and varnishes-colorimetrypart 2: colour measurement (Revision of ISO 7724-2: 1984)

Jablonský M, Šmatko L, Botková M, Tiňo R, Šima J (2016) Modification of wood wettability (European beech) by diffuse coplanar surface barrier discharge plasma. Cellul Chem Technol 50(1):41-48

Kelar J, Čech J, Slavíček P (2015) Energy efficiency of planar discharge for industrial applications. Acta Polytech 55(2):109-112. https://doi.org/10.14311/AP.2015.55.0109

Kim CY, Goring DAI (1971) Corona-induced bonding of synthetic polymers to wood. Pulp Pap Mag Canada 72:93-96

Kogelschatz U (2003) Dielectric-barrier discharges: their history, discharge physics, and industrial applications. Plasma Chem Plasma Process 23:1-46

Král P, Ráhel J, Stupavská M, Šrajer J, Klímek P, Kumar Mishra P, Wimmer R (2015) XPS depth profile of plasma-activated surface of beech wood (Fagus sylvatica) and its impact on polyvinyl acetate tensile shear bond strength. Wood Sci Technol 49:319-330. https://doi.org/10.1007/ s00226-014-0691-7

Kuchenbecker M, Bibinov N, Kaemlimg A, Wandke D, Awakowicz P, Viöl W (2009) Characterization of DBD plasma source for biomedical applications. J Phys D: Appl Phys 42:045212. https://doi.org/10.1088/0022-3727/42/4/ 045212

Law VJ, Anghel SD (2012) Compact atmospheric pressure plasma self-resonant drive circuits. J Phys D Appl Phys 45:075202. https://doi.org/10.1088/0022-3727/45/7/ 075202

Lazovic S, Puac N, Radic N, Hoder T, Malovic G, Rahel J (2008) Mass spectrometry of diffuse coplanar surface barrier discharge. publications of the astronomical observatory of Belgrade 84, 401-404. Bibliographic Code: 2008POBeo..84..401L

Lee DY, Yang JH, Cho BH (2003) Novel energy-recovery driving circuit for plasma display panel using regenerative transformer. In: IEEE 34th annual conference on power electronics specialist, PESC '03. https://doi.org/10.1109/ pesc. 2003.1218133

Lieberman MA, Lichtenberg AJ (2005) Principles of plasma discharges and materials processing, 2nd edn. Wiley, Wiley, Hoboken, New Jersey, USA. ISBN 0-471-72001-1

Lukowsky D, Horn G (2002) Pretreatments of wood to enhance the performance of outdoor coatings. Macromol Symp 187(1):77-86. https://doi.org/10.1002/15213900(200209)187:1\%3c77::AID-MASY77\%3e3.0.CO;2$\mathrm{T}$
Lux C, Szalay Z, Beikircher W, Kováčik D, Pulker HK (2013) Investigation of the plasma effects on wood after activation by diffuse coplanar surface barrier discharge. Untersuchung der Effekte auf Holz nach einer Plasmaaktivierung mit einer Diffuse Coplanar Surface Barrier Discharge (DCSBD) Quelle. Eur J Wood Wood Prod 71:539-549. https://doi.org/10.1007/s00107-013-0706-3

Mai C, Militz H (2004) Modification of wood with silicon compounds. Treatment systems based on organic silicon compounds-a review. Wood Sci Technol 37:453-461. https://doi.org/10.1007/s00226-004-0225-9

Meteo (2020) National Meteorological Service of SloveniaArchiv. http://meteo.arso.gov.si/met/en/climate/current/ last-12-months/archive/, 2020. Accessed 6 Nov 2020

Mishima T, Ooue Y, Fukumoto Y, Nakaoka M (2009) An active rectifier-phase shifted ZVS-PWM DC-DC converter with $\mathrm{HF}$ planar transformer-link for RF plasma power generator. In: 2009 International conference on power electronics and drive systems (PEDS). https://doi.org/10.1109/peds.2009. 5385771

Mizeraczyk J, Hrycak B, Jasinski M, Dors M (2012) Spectroscopic investigations of plasma generated by waveguidesupplied nozzleless microwave sources. Int $\mathrm{J}$ Plasma Environ Sci Technol 6(3):239-245

Mošovská S, Medvecká V, Gregová M, Tomeková J, Valík L, Mikulajová A, Zahoranová A (2019) Plasma inactivation of Aspergillus flavus on hazelnut surface in a diffuse barrier discharge using different working gases. Food Control 104:256-261. https://doi.org/10.1016/j.foodcont.2019.05. 003

Odrášková M, Szalay Z, Ráhel' J, Zahoranová A, Černák M (2007) Diffuse coplanar surface barrier discharge assisted deposition of water repellent films from N2/HMDSO mixtures on wood surface. 28th ICPIG, July 15-20, 2007, Prague, Czech Republic

Odrášková M, Ráhel' J, Zahoranová A, Tiňo R, Černák M (2008) Plasma activation of wood surface by diffuse coplanar surface barrier discharge. Plasma Chem Plasma Process 28:201-211. https://doi.org/10.1007/s11090-0079117-8

Országh J, Danko M, Ribar A, Matejčík Š (2012) Nitrogen second positive system studied by electron induced fluorescence. Nucl Instrum Methods Phys Res Sect B 279:76-79. https://doi.org/10.1016/j.nimb.2011.10.031

Pancheshnyi S (2006) Comments on "Intensity ratio of spectral bands of nitrogen as a measure of electric field strength in plasmas." J Phys D: Appl Phys 39:1708. https://doi.org/10. 1088/0022-3727/39/8/N01

Pandey KK (2005) Study of the effect of photo-irradiation on the surface chemistry of wood. Polym Degrad Stab 90(1):9-20. https://doi.org/10.1016/j.polymdegradstab. 2005.02.009

Paris P, Aints M, Valk F, Plank T, Haljaste A, Kozlov KV, Wagner HE (2005) Intensity ratio of spectral bands of nitrogen as a measure of electric field strength in plasmas. J Phys D Appl Phys 38:3894. https://doi.org/10.1088/00223727/38/21/010

Paris P, Aints M, Valk F, Plank T, Haljaste A, Kozlov KV, Wagner HE (2006) Reply to comments on "Intensity ratio of spectral bands of nitrogen as a measure of electric field 
strength in plasmas." J Phys D Appl Phys 39:2636. https:// doi.org/10.1088/0022-3727/39/12/N01

Peters F, Hünnekens B, Wieneke S, Militz H, Ohms G, Viöl W (2017) Comparison of three dielectric barrier discharges regarding their physical characteristics and influence on the adhesion properties on maple, high density fiberboards and wood plastic composite. J Phys D 50:475206. https://doi. org/10.1088/1361-6463/aa8fad

Peters F, Hünnekens B, Wieneke S, Militz H, Ohms G, Viöl W (2018) Corrigendum: comparison of three dielectric barrier discharges regarding their physical characteristics and influence on the adhesion properties of maple, high density fiberboard and wood plastic composite (2017 J Phys D Appl Phys 50 475206). J Phys D 51: https://doi.org/10. 1088/1361-6463/aab378

Petrič M (2013) Surface modification of wood: a critical review. Rev Adhes Adhes 1:216-247. https://doi.org/10.7569/ RAA.2013.097308

Pitchford CL (2013) GEC plasma data exchange project. J Phys D 46:330301. https://doi.org/10.1088/0022-3727/46/33/ 330301

Podgorski L, Bousta C, Schambourg F, Maguin J, Chevet B (2001) Surface modification of wood by plasma polymerization. Pigm Resin Technol 31:33-40. https://doi.org/10. 1099/03699420210412575

Prysiazhnyi V, Cernak M (2012) Air plasma treatment of copper sheets using diffuse coplanar surface barrier discharge. Thin Solid Films 520(21):6561-6565. https://doi.org/10. 1016/j.tsf.2012.06.069

Radić N, Houska J, Havel J, Nasadil P, Kováčik D (2009) Application of diffuse coplanar surface barrier discharge for textile treatment. In: WDS'09 proceedings of contributed papers, Part II, 106-110, 2009

Radić N, Obradović BM, Kostić M, Dojčinović B, Hudcová M, Kuraica MM, Černák M (2013) Deposition of gold nanoparticles on polypropylene nonwoven pretreated by dielectric barrier discharge and diffuse coplanar surface barrier discharge. Plasma Chem Plasma Process 33:201-218. https://doi.org/10.1007/s11090-012-9414-8

Ráhel' J, Sherman DM (2005) The transition from a filamentary dielectric barrier discharge to a diffuse barrier discharge in air at atmospheric pressure. J Phys D Appl Phys 38:547. https://doi.org/10.1088/0022-3727/38/4/006

Ráhel' J, St'ahel P, Odrášková M (2011) Wood surface modification by dielectric barrier discharges at atmospheric pressure. Chem Listy 105:s125-s128

Rossi S, Fedel M, Petrolli S, Deflorian F (2016) Accelerated weathering and chemical resistance of polyurethane powder coatings. J Coat Technol Res 13:427-437. https://doi. org/10.1007/s11998-015-9764-2

Rosu D, Rosu L, Cascaval CN (2009) IR-change and yellowing of polyurethane as a result of UV irradiation. Polym Degrad Stabil 94(4):591-596. https://doi.org/10.1016/j. polymdegradstab.2009.01.013

Schutze A, Jeong JY, Babayan SE, Park J, Selwyn GS, Hicks RF (1998) The atmospheric-pressure plasma jet: a review and comparison to other plasma sources. IEEE Trans Plasma Sci 26(6):1685-1694. https://doi.org/10.1109/27.747887

Šerá B, Šerý M, Zahoranová A, Tomeková J (2021) Germination improvement of three pine species (Pinus) after diffuse coplanar surface barrier discharge plasma treatment.
Plasma Chem Plasma Process 41:211-226. https://doi.org/ 10.1007/s11090-020-10128-5

Setoyama K (1996) Surface modification of wood by plasma treatment and plasma polymerization. J Photopolym Sci Technol 9:243-250

Šimor M, Ráhel J, Vojtek P, Černák M (2002) Atmosphericpressure diffuse coplanar surface discharge for surface treatments. Appl Phys Lett 81:2716. https://doi.org/10. 1063/1.1513185

SIST EN ISO 2409:1997, Paints and varnishes-cross-cut test

SIST EN 927-3:2001/AC2002, Paints and varnishes-Coating materials and coating systems for exterior wood - Part 3: Natural weathering test

SIST EN ISO 2813:1999, Paints and varnishes-Determination of specular gloss of non-metallic paint films at $20^{\circ}, 60^{\circ}$ and $85^{\circ}$ (ISO 2813:1994, including Technical Corrigendum $1: 1997)$

SIST EN16492:2014, Paints and varnishes_evaluation of the surface disfigurement caused by fungi and algae on coatings

Srinivasa K, Pandey KK (2012) Photodegradation of thermally modified wood. J Photochem Photobio B 117:140-145. https://doi.org/10.1016/j.jphotobiol.2012.09.013

Štěpánová V, Slavíček P, Valtr M, Buršíková V, Stupavská M (2015) Improvement of glass wettability using diffuse coplanar surface barrier discharge and gliding arc considering aging effect. In: Proceedings of the 7th International Conference on Nanomaterials - Research \& Application. pp 321-326. ISBN: 978-80-87294-59-8

Stepanova V, Kelar J, Galmiz O, Zemanek M, Slavicek P, Bucek A, Cernak M (2017) Areal homogeneity verification of plasma generated by diffuse coplanar surface barrier discharge in ambient air at atmospheric pressure. Contrib Plasma Phys 57(4):182-189. https://doi.org/10.1002/ctpp. 201600093

Talviste R, Galmiz O, Stupavská M, Tučeková Z, Kaarna K, Kováčik D (2019) Effect of DCSBD plasma treatment on surface properties of thermally modified wood. Surf Interface 16:8-14. https://doi.org/10.1016/j.surfin.2019. 04.005

Thomas M, Mittal KL (2013) Atmospheric pressure plasma treatment of polymers: relevance to adhesion. Wiley, Hoboken, New Jersey, USA and Scrivener Publishing LLC, Salem, Massachusetts, USA. ISBN 978-1-11859621-0

Tino R, Smatko L (2014) Modifying wood surfaces with atmospheric diffuse coplanar surface barrier discharge plasma. Wood Fiber Sci 46(4):459-464

Tóth A, Černáková L, Černák M, Kunovská K (2007) Surface analysis of groundwood paper treated by diffuse coplanar surface barrier discharge (DCSBD) type atmospheric plasma in air and in nitrogen. Holzforschung 61(5):528-531. https://doi.org/10.1515/HF.2007.080

Tučeková Z, Zahoranová A, Ruščák M, Kováčik D, Černák M (2013) Optical emission spectroscopy of diffuse coplanar surface barrier discharge. In: WDS'13 proceedings of contributed papers, Part II, 144-148

Viöl W, Avramidis G, Militz H (2012) Plasma treatment of wood. In: Rowell, RM (ed) Handbook of wood chemistry and woodcomposites, 2nd edn. CRC press, Boca Raton, Florida, 2012, pp 627-657. ISBN 978-1-439-85380-1 
Wallenhorst LM, Gurău L, Gellerich A, Militz H, Ohms G, Viöl $\mathrm{W}$ (2018) UV-blocking properties of $\mathrm{Zn} / \mathrm{ZnO}$ coatings on wood deposited by cold plasma spraying at atmospheric pressure. Appl Surf Sci 434:1183-1192. https://doi.org/10. 1016/j.apsusc.2017.10.214

Wascher R, Kühn C, Avramidis G, Bicke S, Militz H, Ohms G, Viöl W (2017) Plywood made from plasma-treated veneers: melamine uptake, dimensional stability, and mechanical properties. J Wood Sci 63:338-349. https://doi. org/10.1007/s10086-017-1632-5

Wijnen B, Hunt EJ, Anzalone GC, Pearce JM (2014) Opensource syringe pump library. PLoS ONE 9(9):e107216. https://doi.org/10.1371/journal.pone.0107216

Xiao D, Cheng C, Shen J, Lan Y, Xie H, Shu X, Meng Y, Li J, Chu PK (2014) Characteristics of atmospheric-pressure non-thermal $\mathrm{N}_{2}$ and $\mathrm{N}_{2} / \mathrm{O}_{2}$ gas mixture plasma jet. J Appl Phys 115:033303. https://doi.org/10.1063/1.4862304

Yan W, Han ZJ, Liu WZ, Lu XP, Phung BT, Ostrikov K (2013) Designing atmospheric-pressure plasma sources for surface engineering of nanomaterials. Plasma Chem Plasma Process 33:479-490. https://doi.org/10.1007/s11090-0139441-0

Zeniou A, Puač N, Škoro N, Selaković N, Dimitrakellis P, Gogolides E, Petrović ZLJ (2017) Electrical and optical characterization of an atmospheric pressure, uniform, large-area processing, dielectric barrier discharge. J Phys D Appl Phys 50:135204. https://doi.org/10.1088/1361-6463/ aa5d69

Žigon J, Petrič M, Dahle S (2018) Dielectric barrier discharge (DBD) plasma pretreatment of lignocellulosic materials in air at atmospheric pressure for their improved wettability: a literature review. Holzforschung 72:979-991

Žigon J, Ayata Ü, Zaplotnik R, Petrič M, Dahle S (2019) The influence of artificial weathering and treatment with FEDBD plasma in atmospheric conditions on wettability of wood surfaces. Bull Mater Res Eng. https://doi.org/10. 21268/20190318-13

Žigon J, Kovač J, Zaplotnik R, Saražin J, Šernek M, Petrič M, Dahle S (2020a) Enhancement of adhesives strength of wood-metal joints using atmospheric plasma treatment. Cellulose 27:6411-6424. https://doi.org/10.1007/s10570020-03212-8

Žigon J, Pavlič M, Kibleur P, Van den Bulcke J, Petrič M, Van Acker J, Dahle S (2020b) Treatment of wood with atmospheric plasma discharge: study of the treatment process, dynamic wettability and interactions with a waterborne coating. Holzforschung, accepted for publication/ahead of print. https://doi.org/10.1515/hf-2020-0182

Zin RM, Soon CF, Sani MZA, Rizon ER, Tee KS, Ahmad MK, Ahmad NN, Jubadi WM, Nayan N (2017) Zero voltage switching driver and flyback transformer for generation of atmospheric pressure plasma jet. AIP Conf Proc 1883:020023. https://doi.org/10.1063/1.5002041

Publisher's Note Springer Nature remains neutral with regard to jurisdictional claims in published maps and institutional affiliations. 